\title{
LAS ÁNForas de Brindisi en la Hispania Citerior. PAUtAS DE Distribución
} Y CONSUMO

Brindisi Amphorae in the Hispania Citerior Province. Patterns of Distribution and Consumption

CÉSAR CARRERAS MONFORT ${ }^{1}$, ALBERT MARTÍN MENÉNDEZ ${ }^{2}$, JOAQUIM PERA ISERN ${ }^{1}$, ESTHER RODRIGO REQUENA ${ }^{3}$

(1) Universitat Autònoma de Barcelona.cesar.carreras@uab.cat, joaquim.pera@uab.cat

(2) Ajuntament de Cabrera de Mar.

(3) Institut Català d'Arqueologia Clàssica - Universitat Autònoma de Barcelona. erodrigo@icac.cat

\section{RESUMEN:}

En nuestro estudio ${ }^{I}$ partimos de la premisa que las ánforas brindisinas que llegan a la península Ibérica, abarcando una amplia cronología que podemos establecer entre el 150 y 50 a.C., pueden relacionarse, en muchos casos, con la presencia de unas élites itálicas civiles y militares que intervenían en las organización territorial y conquista de provincias Citerior y Ulterior. Estos envases contenían mayoritariamente aceite de oliva y en menor medida vino. Creemos que las ánforas brindisinas pueden ser un buen indicador arqueológico, entre otros, para conocer mejor la evolución del proceso de la conquista e implantación romana en Hispania, sobre todo para la $2^{a}$ mitad de siglo II a.C., un período para el que aun disponemos de pocas evidencias arqueológicas.

Palabras clave: Brindisi, ánfora, aprovisionamiento, comercio aceite, Siglo II - I a.C., Hispania Citerior.

Abstract:

In our study we propose that the Brindisi amphorae arrived at the Iberian Peninsula during a chronological period from 150 to 50 BC. This could be related in many cases with the presence of Italian civilian and military elites who intervened in the organisation and conquest of the Citerior and Ulterior provinces. Those containers mainly carried olive-oil and to less extent wine. We believed that the Brindisi amphorae are excellent archaeological indicators, among other things, of the evolution of Roman conquest and settlement of Hispania. This indicator is especially useful for the second half of the 2 nd cent. BC in which we have scarse well-dated archaeological evidence.

Key words: Brindisi, amphora, supply, olive-oil trade, 2nd-1st cent. BC, Hispania Citerior.

Copyright: (C) 2016 César Carreras et al. This is an open access paper distributed under the terms of 


\section{LA PRODUCCIÓN ALFARERA EN EL TERRITO- RIO DE BRINDISIUM: LAS ÁNFORAS APULIOTAS}

Estas ánforas se producían en talleres situados en las proximidades de Brundisium; los mejor conocidos son los talleres de Apani y Giancola en la costa, Marmorelle en el interior y La Rosa en la zona portuaria del S; todos ellos enlazados por la vía costera de Minucia (ver fig. 2). La primera mención de esta zona productora fue a través de la epigrafía anfórica recogida en el CIL IX (613-615) bajo el epíteto de envases calabreses; pero será a partir de la excavación del centro alfarero de Apani que se establece una primera clasificación tipológica para las producciones de esta alfarería (Palazzo 1988); asimismo Desy recoge en otro estudio buena parte de la epigrafía anfórica de la Apulia republicana (Desy 1989). Las ánforas brindisinas tuvieron una amplia distribución en todo el Mediterráneo desde el tercer cuarto del s. II a.C. hasta mediados del s. I a.C.. Además de la península Itálica, se distribuyeron por Sicilia, Córcega, Cerdeña, Hispania, S de la Gallia, Grecia (Atenas y Delos sobre todo), Efeso, Chipre, Próximo Oriente, Alejandría, etc. (Cipriano y Carré 1989; Desy 1989; Palazzo 2013).

Las publicaciones de Palazzo (1988; 1989; 1992; 1994) sirvieron para crear una primera tabla tipológica con cuatro formas, bajo la denominación genérica Apani, definidas a partir de ejemplares completos; de estas cuatro formas iniciales derivaban ocho grupos definidos a partir de diferencias observadas en la parte superior de las ánforas: bordes, cuellos y asas. La gran variabilidad en los acabados de estas ánforas hacía difícil el uso de esta tabla tipológica. Actualmente la tipología se ha simplificado con la creación de una nueva tabla elaborada a partir del estudio de la alfarería de Giancola (Manacorda; Pallechi 2012) y una nueva versión de Apani con siete tipos (Palazzo 2013). En el último trabajo sobre Giancola se han establecido cinco tipos básicos, respetando las equivalencias a la primera tipología de Apani.

\section{GIANCOLA 1 (Apani II - grupo VII de Palazzo 1988)}

Ánfora de pequeñas dimensiones, cuerpo ovoide y pivote en forma de botón. Muestra un labio exvasado de perfil moldurado y asas cortas de sección circular. Comienza a producirse a partir de la segunda mitad del s. II a.C. (Volpe 1990; 1995). En las excavaciones de Giancola, esta forma se fecha en el primer período de producción de la alfarería, entre 150-50 a.C. (Manacorda y Pallechi 2012: 146).

\section{GIANCOLA 2 (Apani I)}

Ánfora de cuerpo ovoide, acabada en un sólido pivote diferente al resto de tipos. Tiene un labio triangular y asas de sección ovalada. Se fecha en la segunda mitad del s. II hasta mediados de s. I a.C., la evidencia más antigua se documenta en Adria en la segunda mitad del s. II a.C. (Toniolo 2000). Es una tipología que se ha asociado con la tradición de ánforas greco-itálicas de Salento, parecida a la Lamboglia 2, que constituye el envase clásico de vino del Adriático.

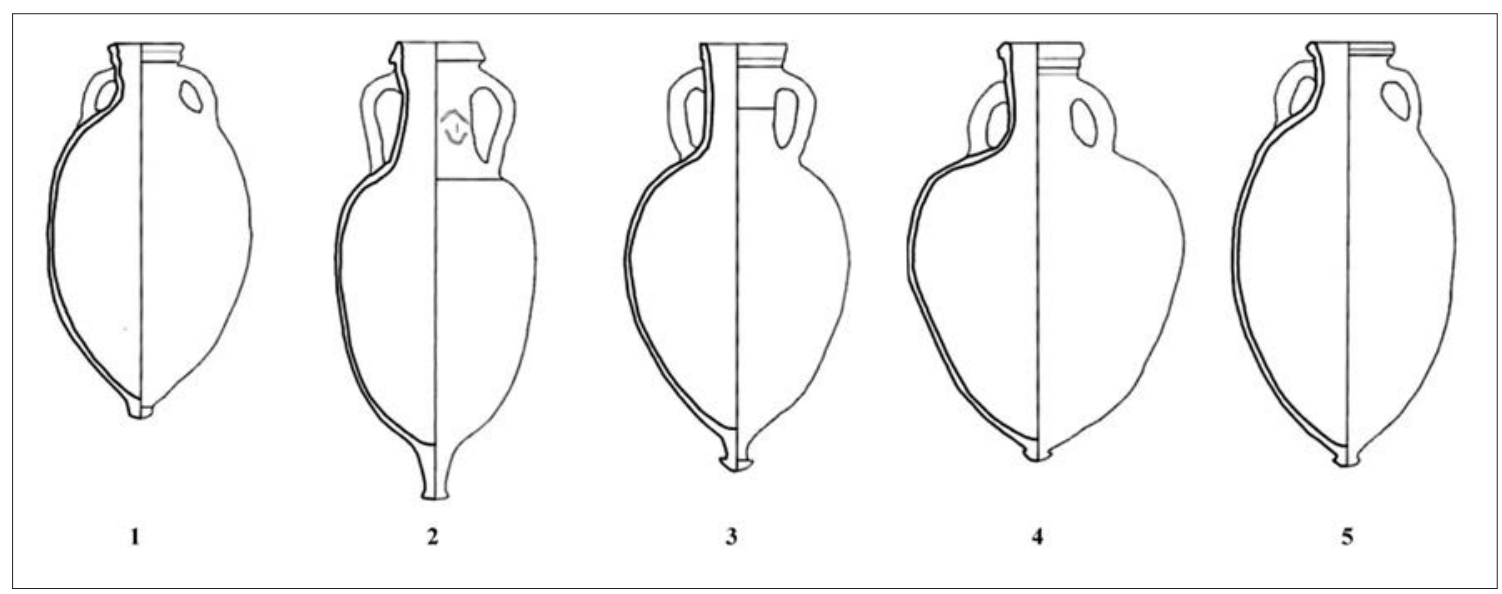

Fig. 1: Tabla tipológica de las ánforas de Giancola (Manacorda y Pallechi 2012: 104, fig.3.1) - Giancola 1 (Apani II), Giancola 2 (Apani I), Giancola 3 (Apani II), Giancola 4 (Apani IV) y Giancola 5 (Apani III). 
Fig. 2: Mapa de alfarerías de Brindisi (adaptación de Manacorda y Pallechi 2012: fig. 1.7)

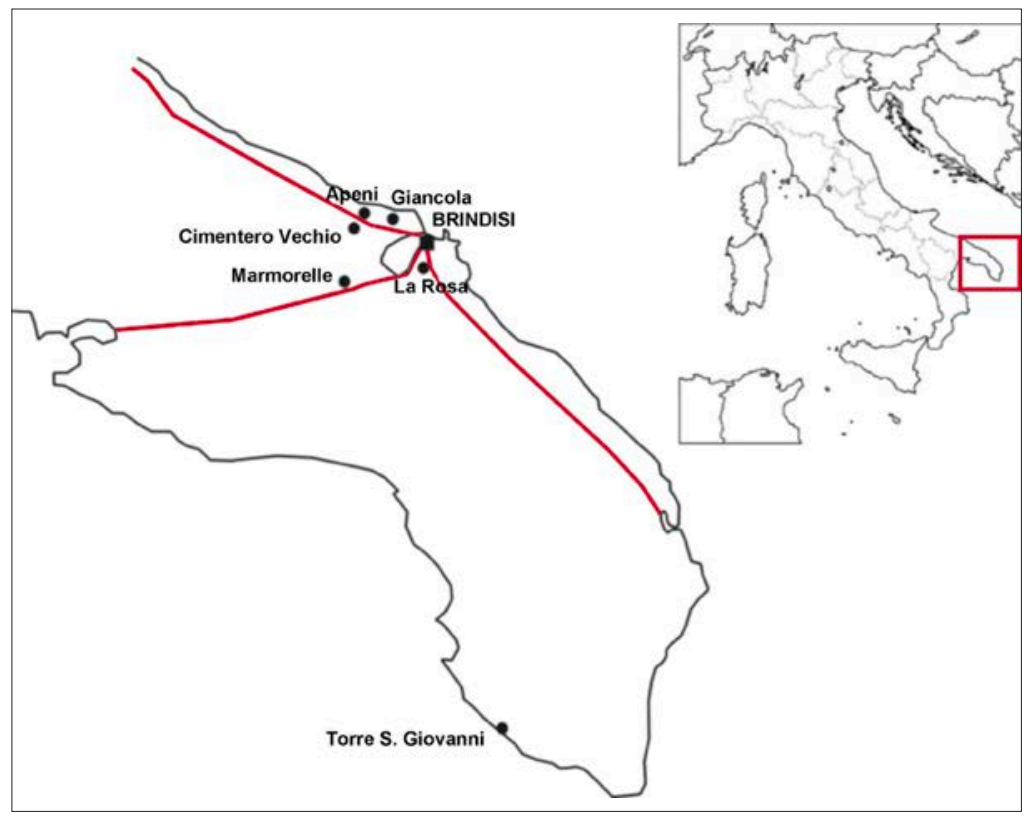

\section{GIANCOLA 3 (Apani II)}

Ánfora ovoide muy parecida a la Giancola I pero de mayores dimensiones, un pivote en forma de botón bien desarrollado, labio exvasado con una pequeña moldura. Se asocia a la marca Aniniana de Apani, y se produce en Apani, Giancola y en Torre San Giovanni (Desy y De Paepe 1990, 223, n.224, Tav.97). Se considera un ánfora olearia de unos 35 litros, que seguía un modelo de envase corintio. Algunos ejemplares se fechan por primera vez a finales del s. II a.C.

\section{GIANCOLA 4 (Apani IV)}

Es un ánfora ovoide con pivote en forma de botón. El labio es exvasado, moldurado pero acabado con borde redondeado. Se fecha desde finales del s. II a.C. (ágora de Atenas y Cosa) hasta el tercer cuarto del s. I a.C. Y se produce en Giancola, La Rosa y Torre San Giovanni.

\section{GIANCOLA 5 (Apani V)}

Ánfora ovoide con pivote en forma de botón y asas cortas. Se caracteriza por un cuello pequeño rematado por un borde corto redondeado. Se trata de uno de los tipos más difundidos en el Mediterráneo Occidental, sobretodo en la península Ibérica. Se produce en Apani,
Marmorelle, Giancola, y en menor medida en La Rosa y Torre San Giovanni (Ugento). Se fecha en contextos de finales del s. II y principios del I a.C.; está representada en los pecios de Spargi y Adria (Toniolo 2000). En el pecio de Escombreras II (90-80 a.C.) se encuentra asociada a la Dressel 1 y Lamboglia 2 (Alonso y Pinedo 2007).

En general se considera que sólo la forma Giancola 2 (Apani I) envasaba vino; mientras que el resto de envases transportaban aceite, producto por el cual era famosa la región. Las industrias alfareras que fabricaron estos envases se hallan próximas al puerto de la colonia de Brundisium (Giancola, Apani, Marmorelle y La Rosa), aunque la gran diversidad de pastas documentadas sugiere la existencia de más talleres. En la reciente publicación de Giancola (Manacorda y Pallechi 2012) se recoge un amplio estudio arqueométrico de Gloria Olcese detallando las pastas cerámicas características de Giancola, a la que se suma la de Marmorelle (Patterson y Olcese 2012), en ellas se distinguen hasta tres grupos de pastas diferentes a nivel petrográfico ${ }^{2}$. Fuera del ámbito itálico disponemos de algunos análisis petrológicos de ánforas brindisinas, por ejemplo en Éfeso (Bezeczky 2013, 110-114), donde aparecen representadas las 5 formas de la tipología de Giancola en contextos entre mediados de s. II a.C. hasta el I a.C. donde algunas de las muestras coinciden totalmente con las pastas conocidas de Giancola ${ }^{3}$. 

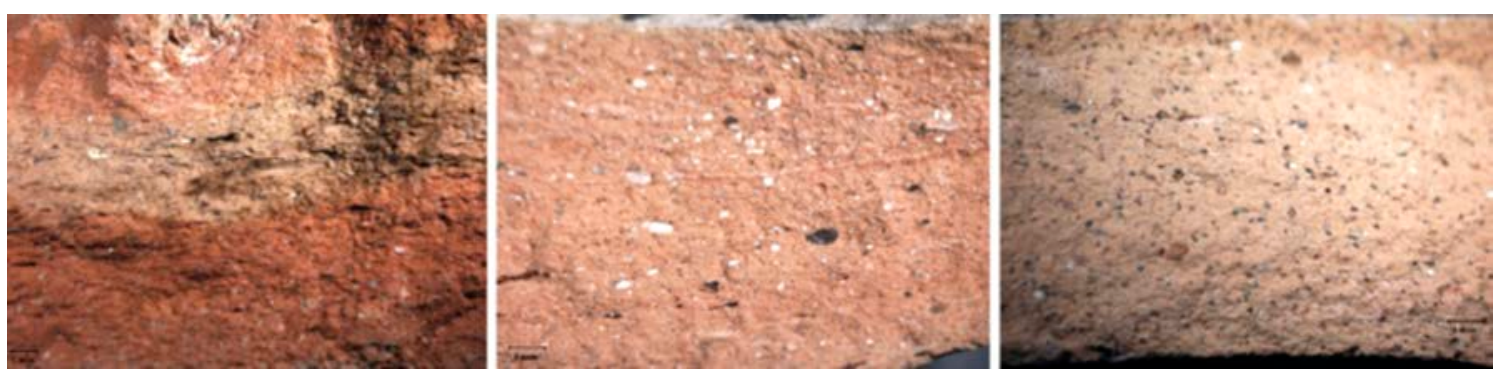

Fig. 3: Imagen macroscópica de pastas cerámicas del Grupo I de Giancola documentadas en Guissona.

También disponemos de análisis arqueométricos para cuatro ejemplares hallados en las fosas fundacionales de la ciudad romana de Iesso (Guissona) (Guitart et al. 1998: 50) que vienen a confirmar la caracterización de Patterson y Olcese, su descripción petrológica coincide perfectamente con la pasta del Grupo I de Giancola.

Otro de los elementos fundamentales para el estudio de las ánforas brindisinas es su epigrafía; los sellos se encuentran habitualmente estampillados en las asas del ánfora. En ocasiones, pueden encontrarse hasta dos marcas diferentes una en cada una de las asas. Cabe observar que no todas las formas muestran sellos por igual, siendo la Giancola 5 (Apani V) la que muestra más ejemplares con sellos. A partir de los nombres podemos establecer tres grupos de marcas, todas ellas en grafía latina y solo una en griega: Un primer grupo corresponde a nombres serviles, mayoritariamente de origen griego, como Aeneas, Apelles, Diototus, Andronicus o Apollonides; el otro grupo recoge nombres de personas de condición libre, identificados a partir de tria nomina, duo nomina o tan sólo cognomina y una tercera de figlinae como Aniniana o Vehiliana (Desy 1989; Manacorda y Pallechi 2012: 293-408; Palazzo 2013: 34). Muchos de estos nombres son atestiguados en la epigrafía monumental de la zona de Puglia; familias bien conocidas en la región donde algunas ejercieron cargos públicos. Podemos citar como ejemplo el caso de Cottidiano, esclavo de C.Apuleyo Flaco (AE 1966: 88) (Manacorda 1994: 12-14) o la marca Tarbula, un liberto de L.Sila, que ejercía como institor de sus propiedades en el ager brindisinum.

Como habíamos apuntado anteriormente la distribución de envases brindisinos en Occidente resulta un eficiente parámetro para seguir los movimientos del ejército en estos nuevos territorios. En el caso de la Gallia también es evidente este fenómeno; Loughton demuestra que existe una distribución distinta de las ánforas vinarias (Dressel
1A, Dressel 1B, Dressel 1C, Lamboglia 2) respecto a las olearias (Brindisi y ovoides laciales); estas últimas se concentran casi exclusivamente en las regiones del sur, donde se han documentado en 33 yacimientos (Loughton 2003: 190-191; Palazzo 2013). Cabe recordar que la primera fase de romanización de Gallia se produce en el último cuarto del s. II a.C. con la creación de la provincia de la Gallia Transalpina y la construcción de la vía Domitia (118 a.C.). Las provincias hispanas de la Ulterior y Citerior son anteriores a la creación de la Provincia Gallia Transalpina, por tanto la distribución de ánforas brindisinas resulta aún más reveladora. En la península Ibérica están presentes en gran número de yacimientos con fechas tempranas (desde el tercer cuarto del s. II a.C.), por consiguiente el estudio de su distribución puede aportar datos más precisos para concretar la cronología de cada tipo y valorar la magnitud de este abastecimiento, así como para conocer el movimiento de las tropas en campaña.

\section{EVIDENCIAS DE LAS ÁNFORAS BRINDISINAS EN LA PENÍNSULA IBÉRICA}

La llegada de ánforas brindisinas a la península Ibérica se realiza por vía marítima y con toda seguridad desde el último tercio del s. II a.C., tal como sugieren algunos contextos conocidos y los propios sellos. Los principales puertos de este período son a su vez bases militares: Emporion, Tarraco o Cartago Nova y posteriormente Valentia. En los pecios republicanos conocidos hasta ahora (Asensio 2010) solo aparecen ánforas brindisinas en los naufragios de San Ferreol (Mas 1985) y Escombreras 2 (Alonso y Pinedo 2007) ${ }^{4}$. En el caso de San Ferreol (Mar Menor) fechado entre el 110-80 a.C., junto a las brindisinas aparece un cargamento de ánforas de Chios, Rodas, Kos, Lamboglia 2 y Dressel 1B junto con campaniense B calena. En Escombreras 2, próximo a Cartago Nova, datado 
Fig. 4: Ánforas brindisinas de Ilturo con marca STABVAS (4 y 7) y VISELLI (8).

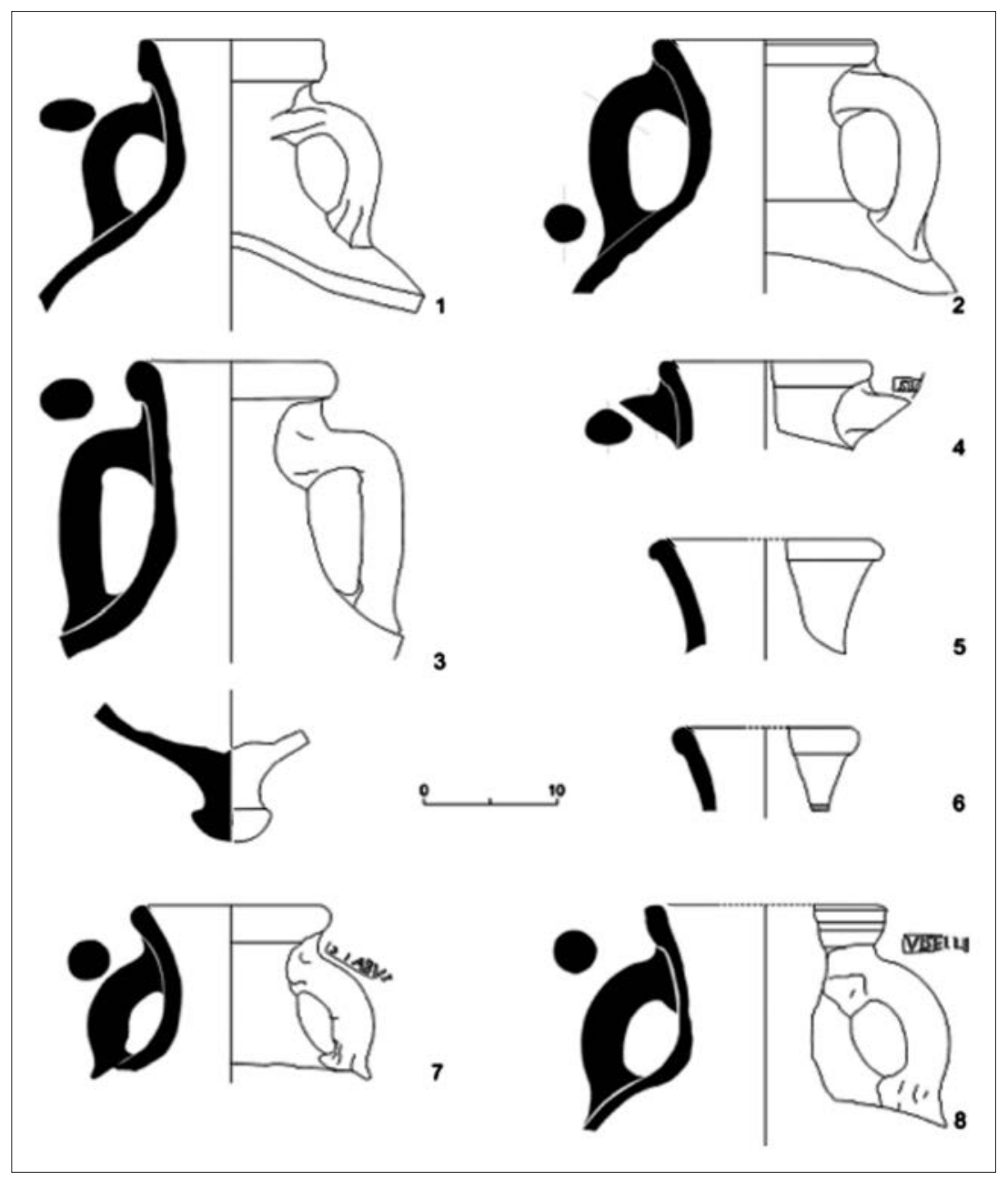

entre 90-80 a.C., aparecen ánforas Dressel 1 (A, B y C), Lamboglia 2 y Giancola 5 con las marcas C.ANINI y CWTEPI (Apani V y grupo VII) junto a lingotes de plomo y campaniense B calena (Alonso y Pinedo 2007).

El panorama que ofrece la arqueología terrestre resulta mucho más rico y complejo por lo que respecta a hallazgos de ánforas de origen brindisino; al menos en 69 yacimientos terrestres hispanos se describen estos envases, sobre todo de las formas Giancola 1 y 5 . Resulta especialmente significativa su presencia en el NE de la península Ibérica y en la zona levantina próxima a Cartago Nova; seguramente al ser estas dos regiones las primeras cabezas de puente del ejército romano en territorio peninsular y las que quedan bajo dominio romano en fechas más tempranas. Uno de los puertos receptores de ánforas brindisinas fue Empúries, donde se tiene la constancia de las marcas: APOLONI, CVEILI, LVCRIO, SALM o VEHIL (Almagro 1952; Berni 1996). Si bien llegarían a partir del último tercio del s. II a.C, en Empúries son más frecuentes encontrarlas en contextos más tardíos, como por ejemplo en los silos cesarianos del área del foro (Aquilué et al. 2002) y en un estudio reciente (Tremoleda y Castanyer 2013: 246-248) en contextos fechados entre el 70-60 a.C (UE99-CR-F283), junto a ánforas Dressel $1 \mathrm{~B}$, egeas y Lamboglia 2.

Un segundo centro de recepción de estos envases fue el enclave romano republicano de Ilturo (Cabrera de Mar) ${ }^{5}$. Este yacimiento presenta una cronología entre mediados del s. II a.C. hasta el primer cuarto de s. I a.C., con perduraciones posteriores muy puntuales. Por ello, la presencia de ánforas brindisinas es común en muchos de sus contextos estratigráficos, aunque en proporciones menores 


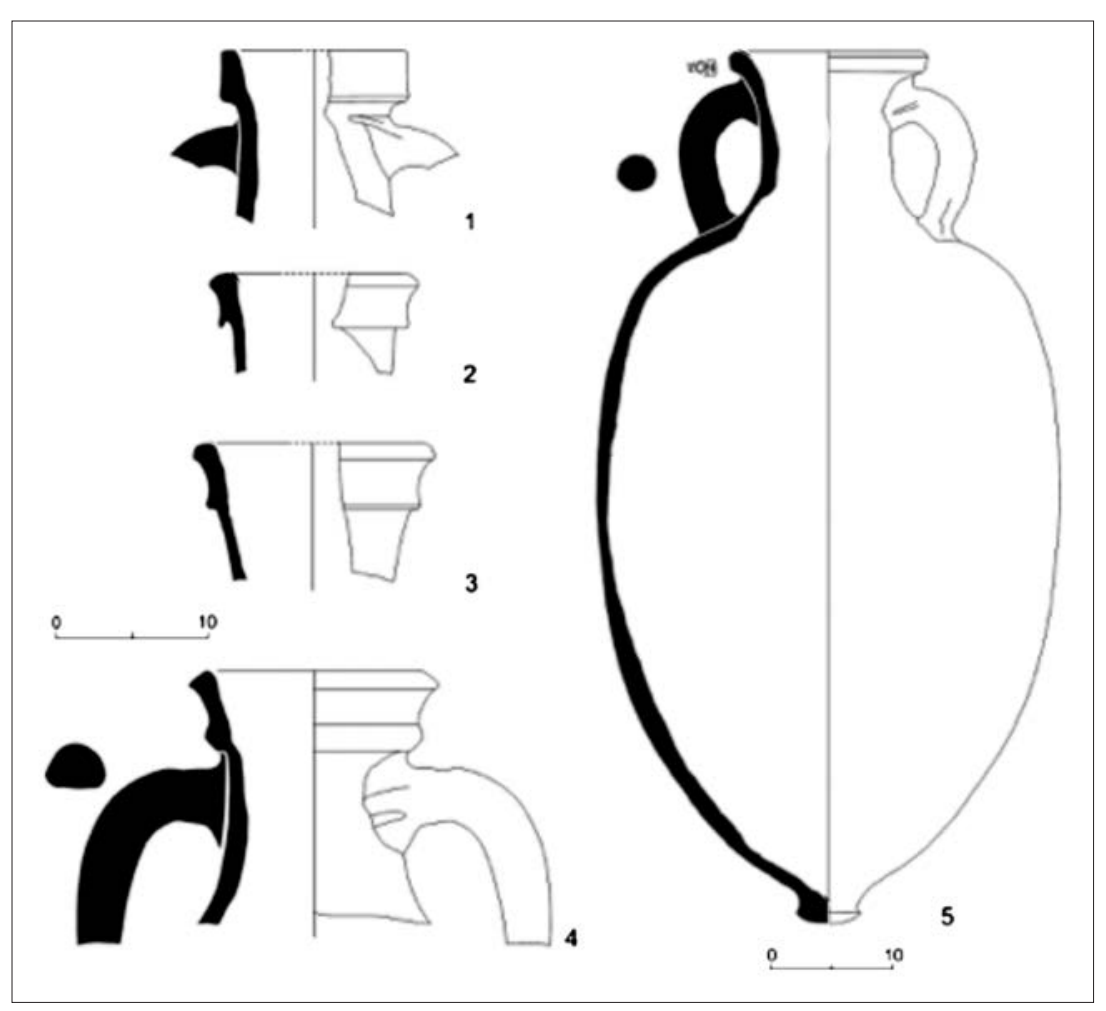

Fig. 5: Ánforas brindisinas de Ilturo con marca Q.OBVLTRON (5).

respecto las producciones vinarias de la Campania. Hasta el momento se han documentado poco más de un centenar de fragmentos de ánforas brindisinas con forma ${ }^{6}$ nueve de ellos de la forma Giancola 5 (Apani V) con cuatro marcas: dos STABVAS (fig. 4.4 y 7), un VISELLI (fig. 4.8) y un Q.OBVLTRON (fig. 5.5); cinco ejemplares de la forma Giancola 1, en sus diversas variantes (fig. 5.1 a 4 y fig. 6.1); cuatro de la forma Giancola 2 (Apani I) (fig. 6.4 a 7); dos de la Giancola 4B (fig. 6.2 y 3 ) y uno de la Giancola 3A (Apani II). El resto no permite su atribución tipológica aunque podemos mencionar cuatro asas con las marcas: APOLONI, STR, SCOPAS y AENEAS, esta última muy desgastada (fig. 6.10 a 13).

Los contextos cronológicos de Ilturo donde aparecen estas ánforas se fechan en los dos primeros decenios del s. I a.C. También se ha registrado la forma Giancola 5 (Apani V) y Giancola 4B en otros contextos entre el 75 y el 50 a.C. (Can Rodon de l'Hort), así como en estratos de cronología posterior como material residual. Los niveles de s. II a.C. con brindisinas son más escasos y proceden del sector de can Benet, son fragmentos de asas en un nivel datado en el 135-125 a.C. y un borde de Giancola 1 (Apani II). Por tanto, se puede concluir que en Ilturo, las producciones anfóricas de Brindisi, están bien atestiguadas desde el último cuarto del s. II a.C. y perdurarán hasta medidos de la centuria siguiente.

Otro de los establecimientos portuarios importantes del NE peninsular durante este período fue Tarraco, del que disponemos de una amplia documentación gracias al excelente trabajo de Moisés Díaz (Díaz 2013), un estudio donde se analizan diversos contextos republicanos. La figura 7 muestra la evolución de las importaciones de ánforas brindisinas (en \% del NMI) respecto al resto de ánforas en distintos períodos. Resulta significativa la proporción en que aparece cada tipo de envase, por ejemplo la forma Giancola 5 (Apani V), con un bajo porcentaje (1,37\% del total), aparece en los contextos más antiguos (153-138 a.C.); la proporción aumenta ligeramente $(2,26 \%)$ en el segundo período entre 138-120 a.C., con la variante posiblemente vinaria de la Giancola 2 (Apani I) y la olearia Giancola 5 (Apani V). Llama la atención el tercer período (120-75 a.C.) donde no existen testimonios de ánforas brindisinas, esto puede obedecer a un fenómeno particular de los contextos estudiados; una ausencia que resulta difícilmente extrapolable a otras zonas, sirva de ejemplo el caso de las fosas fundacionales 
Fig. 6: Ánforas brindisinas de Ilturo con marcas APOLLONI (10), STR (11), SCOPAS (12) y AENEAS (13).

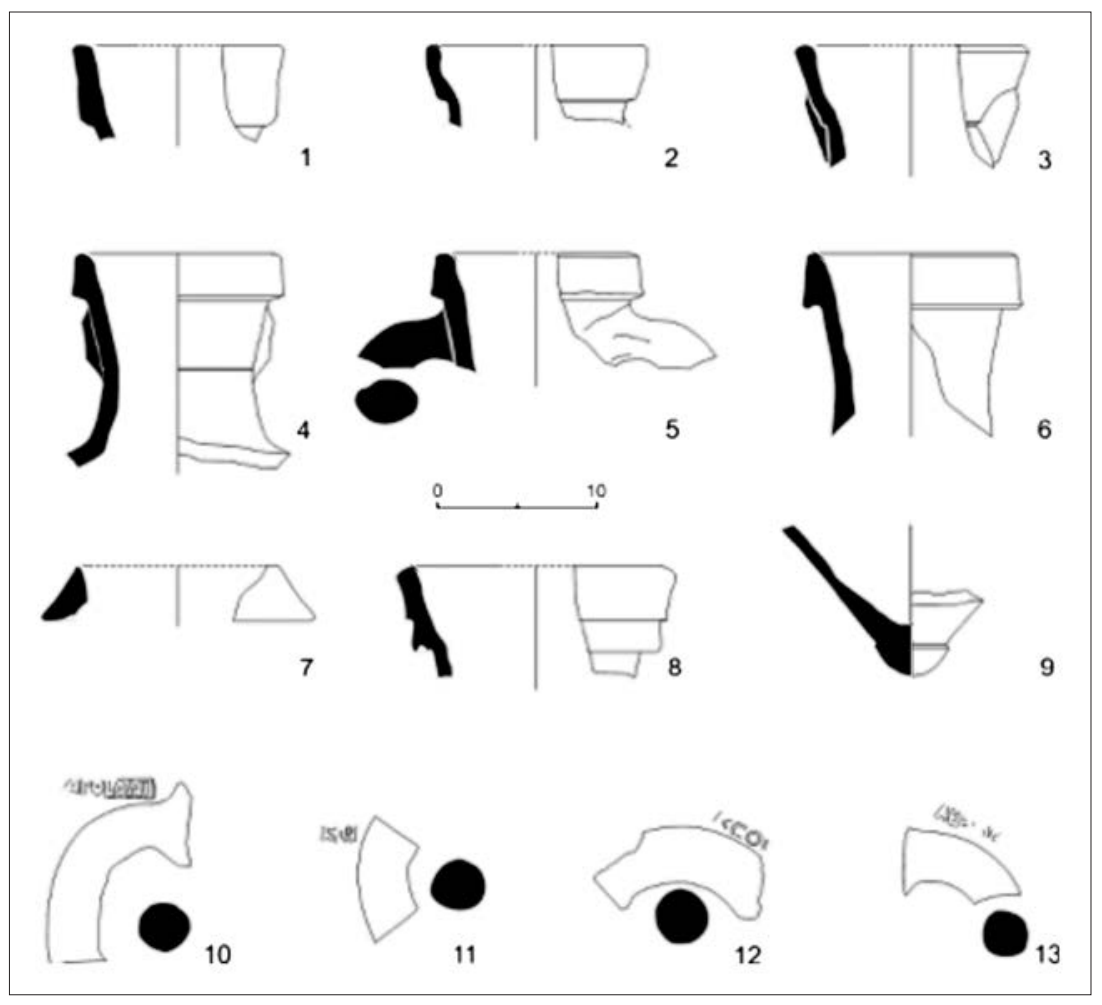

de Iesso (Guissona) donde las ánforas brindisinas aparecen en un contexto bien fechado con esta cronología. Finalmente, durante el período final del 75-50 a.C. se registra en Tarraco un notable incremento de importaciones brindisinas.

Más ejemplos los encontramos en la colonia de Valentia; a destacar una fosa fundacional del 138 a.C. donde ya aparece una ánfora brindisina (Ribera 1995); resulta interesante este contexto puesto que aparece acompañada de otras ánforas olearias como la Tripolitana antigua ${ }^{7}$, ánforas vinarias rodias y púnico-ebusitanas, así como ánforas greco-itálicas de transición y Dressel 1A. También en los contextos de la destrucción de Valentia, fechados alrededor del 75 a.C., se documentan diversos ejemplares de ánforas brindisinas (Ribera 2013). Por último citaremos Cartago Nova, el gran centro portuario del S de la costa levantina, aunque conocemos con menor detalle los contextos republicanos con ánforas brindisinas éstas son comunes (Ballester y Pascual 2004), y además se han documentado un buen número de sellos -un total de 10publicados hace unos años (Márquez y Molina 2005). Algunas de estas marcas proceden de contextos republicanos del anfiteatro.

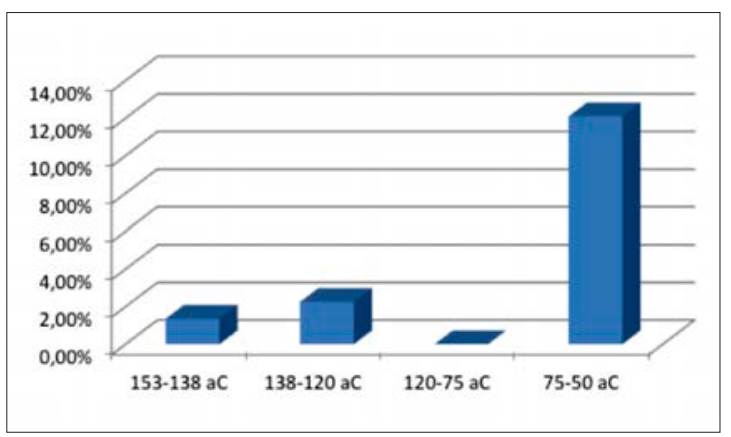

Fig. 7: Distribución de ánforas brindisinas en Tarraco según contextos cronológicos (\% del total de ánforas de cada conjunto según el NMI) (Díaz García 2013).

Seguramente fue desde estos centros costeros Empúries, Ilturo, Tarraco, Valentia y Cartago-Nova desde donde se distribuyeron estas ánforas hacia el interior de la Hispania Citerior. Una imagen aproximada de la distribución de las ánforas brindisinas en la península Ibérica se visualiza en la fig. 8 (ver también figs. 9 y 10) con 69 yacimientos referenciados, en este mapa se observa una especial concentración en las zonas del NE, Valle del Ebro y costa levantina. 


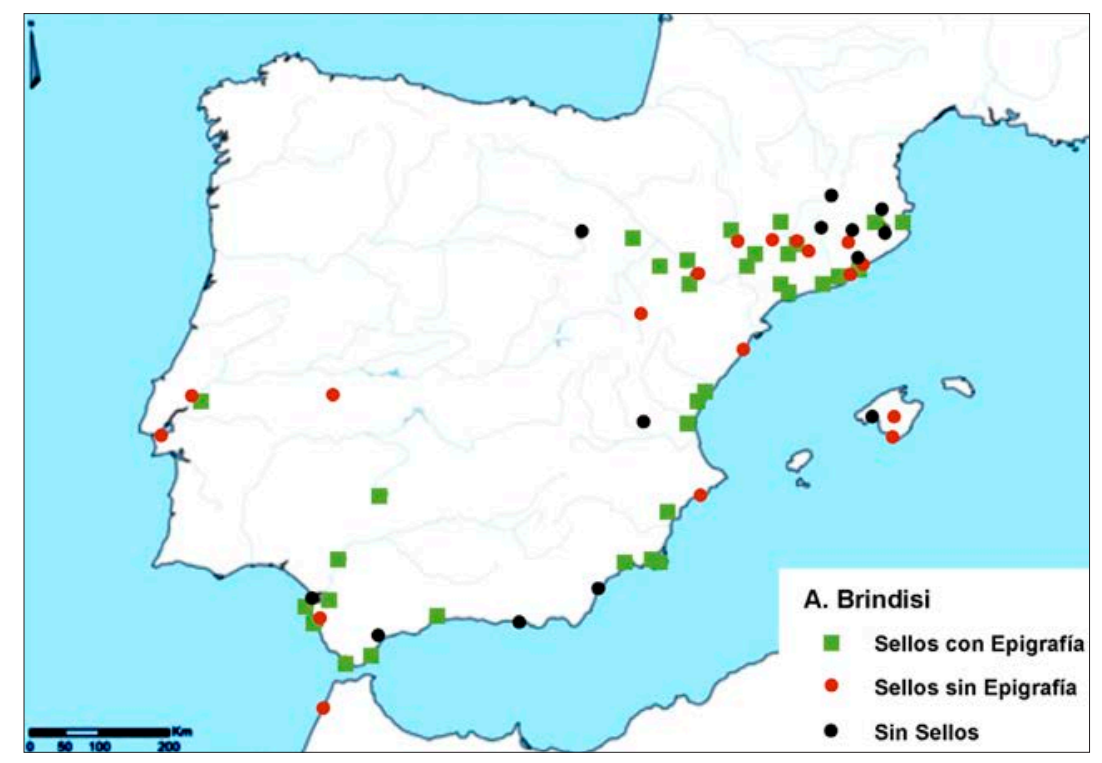

\begin{tabular}{|c|c|c|c|}
\hline Andalucía & $\begin{array}{l}\text { Cerro de Montecristo (Adra) } \\
\text { Lacipo (Malaga) } \\
\text { Puerto de Santa María (Cádiz) } \\
\text { Villaricos }\end{array}$ & Catalunya & $\begin{array}{l}\text { Badalona } \\
\text { Burriac (Mataró) } \\
\text { Camp de les Lloses (Tona) } \\
\text { Can Caseta de Fugurull (Manlleu) }\end{array}$ \\
\hline Aragón & $\begin{array}{l}\text { Caminreal (Teruel) } \\
\text { Celsa (Velilla del Ebro) }\end{array}$ & & $\begin{array}{l}\text { Can Rossell (Llinars) } \\
\text { Can Tacó (Montronés-Montmeló) }\end{array}$ \\
\hline Baleares & $\begin{array}{l}\text { Son Fornés } \\
\text { Son Espases } \\
\text { Torre Llafuda } \\
\end{array}$ & & $\begin{array}{l}\text { Castellot (Bolvir) } \\
\text { Colonia Sant Jordi } \\
\text { Cornellà }\end{array}$ \\
\hline Castilla/León & Numancia & & Els Prats del Rei (Sigarra) \\
\hline \begin{tabular}{|l|} 
Extramadura \\
\end{tabular} & Cáceres el Viejo & & Mataró \\
\hline Galicia & $\begin{array}{l}\text { Castro de Alobre } \\
\text { Santa Tegra }\end{array}$ & & $\begin{array}{l}\text { Monteró } \\
\text { Olriols }\end{array}$ \\
\hline Marruecos & Lixus & & Puig Castell (Samalús) \\
\hline Portugal & $\begin{array}{l}\text { Olisipo } \\
\text { Santarem }\end{array}$ & & $\begin{array}{l}\text { Puig Castellar (Biosca) } \\
\text { Puigpelat }\end{array}$ \\
\hline Valencia & $\begin{array}{l}\text { Casa de la Cabeza (Requena) } \\
\text { Torre de Sal (Benicarló) } \\
\text { Vilajoyosa }\end{array}$ & & $\begin{array}{l}\text { Sant Julià de Ramis } \\
\text { Sant Miquel de Sorba }\end{array}$ \\
\hline
\end{tabular}

Fig. 8: Mapa de distribución de ánforas brindisinas en la península Ibérica.

Fig. 9: Yacimientos peninsulares con presencia de ánforas brindisianas (sin sellos conocidos).
En conjunto si relacionamos las ánforas brindisinas con las ánforas vinarias contemporáneas (greco-itálicas y Dressel 1 en todas sus variantes), veremos que proporcionalmente las brindisinas aparecen en menor cantidad, lo que sugiere que había una menor demanda (Guitart et al. 1998; Ribera 1995; Díaz 2013). Una posible explicación de este fenómeno sería que, si bien el aceite era un producto común en la Roma republicana, su consumo en la península Ibérica estaba poco extendido; esta premisa nos permite presentar al aceite como un producto étnico ligado a la llegada de itálicos a los nuevos territorios ${ }^{8}$, aunque por su volumen no creemos que formara parte de la dieta habitual de la tropa, sino que era consumido solo por algunas élites romanas (oficiales, altos funcionarios, etc.) comportando pues un menor suministro, por ejemplo en comparación al vino.

Por supuesto, la producción de aceite ya se conoce en las sociedades ibéricas como demuestran los hallazgos en contextos del s. V a.C. de Saus (Girona), Font de la Canya (López 2006) o del III a.C. en Els Estinclells (Asensio et al. 2010) $)^{9}$, asociados a prensas utilizadas tanto para producir vino como aceite. Ahora bien, se trata de una producción 


\begin{tabular}{|c|c|c|c|}
\hline Sello & Localización & Sello & Localización \\
\hline ABSAVISELI & Azaila & MCALAMANA & Carthago Nova \\
\hline \multirow[t]{2}{*}{ ACAE } & \multirow{2}{*}{$\begin{array}{l}\text { Carthago Nova } \\
\text { La Alcúdia }\end{array}$} & MENECRATES & Ilerda (Lleida) \\
\hline & & MOE & Azaila \\
\hline \multirow{16}{*}{\begin{tabular}{|l} 
AENEAS \\
APOLONI
\end{tabular}} & Ca l'Arnau & \multirow[t]{2}{*}{ M.TVCCI.L.F.TRO GALEONIS } & Gadir \\
\hline & Azaila & & Badalona \\
\hline & \multirow{2}{*}{\begin{tabular}{|l} 
Baelo \\
Botorrita (2)
\end{tabular}} & NVMENI & Badalona \\
\hline & & MVRVDI & La Alcúdia \\
\hline & \multirow{2}{*}{$\begin{array}{l}\text { Ca l'Arnau } \\
\text { Cabezo Agudo (La Unión) }\end{array}$} & NOVMI & Iesso (Guissona) \\
\hline & & \begin{tabular}{|l|} 
PASTOR \\
\end{tabular} & Puig Castell (Salamús) \\
\hline & \multirow{2}{*}{$\begin{array}{l}\text { El Bosquet } \\
\text { Empúries (2) }\end{array}$} & \begin{tabular}{|l} 
PCLAUDIVISNQ \\
\end{tabular} & Carthago Nova \\
\hline & & PERDICAS & $\begin{array}{l}\text { Fuentes del Ebro } \\
\text { Carthago Nova }\end{array}$ \\
\hline & $\begin{array}{l}\text { lesso (Guissona) } \\
\text { Hispalis }\end{array}$ & \begin{tabular}{|l|l} 
PILBETILM \\
\end{tabular} & Loma de Herrerías (Mazarrón) \\
\hline & \multirow{3}{*}{$\begin{array}{l}\text { La Loba (Fuenteovejuna) } \\
\text { Málaga } \\
\text { Missatge de Claravalls (Tárrega) } \\
\text { Monzón }\end{array}$} & PROMETUS & Azaila \\
\hline & & PTOLOMAE & La Alcúdia \\
\hline & & PUEBAL & $\begin{array}{l}\text { Gebut } \\
\text { Ilerda (Lleida) }\end{array}$ \\
\hline & \multirow{2}{*}{$\begin{array}{l}\text { Sant Boi } \\
\text { Tarraco }\end{array}$} & Q.OBVLTRON & Ca l'Arnau \\
\hline & & SALM & Empúries \\
\hline & \multirow{2}{*}{$\begin{array}{l}\text { Valentia } \\
\text { Vilauba }\end{array}$} & \multirow[t]{3}{*}{ SCOPAS } & Azaila \\
\hline & & & Ca l'Arnau \\
\hline AVIIC $[\ldots$ & Aeso (Isona) & & La Loba (Fuenteovejuna) \\
\hline \multirow{6}{*}{\begin{tabular}{|l|} 
BETIL \\
CANINI \\
\end{tabular}} & Hasta Regia & \multirow[t]{2}{*}{ SOTERIC } & La Alcúdia \\
\hline & \multirow{5}{*}{$\begin{array}{l}\text { Gebut } \\
\text { La Alcúdia } \\
\text { Ilerda (Lleida) } \\
\text { Escombreras } 2 \\
\text { Secuita }\end{array}$} & & Escombreras 2 \\
\hline & & STABVA & Ca l'Arnau (2) \\
\hline & & 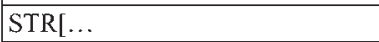 & Ca l'Arnau \\
\hline & & TAVURA & Ca l'Arnau \\
\hline & & \multirow[t]{9}{*}{ VEHILI } & \multirow{9}{*}{\begin{tabular}{|l|} 
Alto dos Cascos \\
Azaila (2) \\
Badalona \\
Borja \\
Chipiona \\
Empúries (3) \\
Puig Castell (Salamús) \\
Torre Llafuda \\
Sant Boi \\
\end{tabular}} \\
\hline CHELVICF & Olérdola & & \\
\hline CERD & Isla del Fraile (Cartagena) & & \\
\hline CHARI & Badalona & & \\
\hline CWTEPI & Escombreras 2 & & \\
\hline DAMA & Sant Feliu de Llobregat & & \\
\hline DASIO & Carthago Nova (2) & & \\
\hline DIONIS & Badalona & & \\
\hline DO...I... & Carthago Nova & & \\
\hline EPIGENE & Iesso (Guissona) & VIPOR & Empúries \\
\hline ERD & Carthago Nova & \multirow[t]{3}{*}{ VISELLI } & Ca l'Arnau \\
\hline \multirow[t]{2}{*}{ FCAN } & L'Horta (Vall d'Uxó) & & Carteia \\
\hline & Sagunto & & Tarraco \\
\hline IERO & Tarraco & ...]ANINIA .../LANINIVS & Empúries \\
\hline \multirow[t]{2}{*}{ LVCCO } & \multirow{2}{*}{\begin{tabular}{|l|} 
Badalona \\
Botorrita (2)
\end{tabular}} & $\ldots]$ EAN $[\ldots$ & Missatge de Claravalls (Tárrega) \\
\hline & & $\ldots \mathrm{JNI}$ & Carthago Nova \\
\hline LVCRIO & Empúries & ...]VENE & Carthago Nova \\
\hline MATIOLEI & Ilerda (Lleida) & & \\
\hline
\end{tabular}

Fig. 10: Listado de sellos de ánforas brindisianas en Hispania.

de aceite limitada, que por las dimensiones de sus prensas y lagares; sería un producto destinado exclusivamente al consumo propio. En ningún caso se observa una producción excedentaria de carácter industrial ni se conoce ningún contenedor local que indiquen una comercialización. En lo que respecta al aceite africano, se documenta a partir de las ánforas púnicas y tripolitanas en contextos indígenas ibéricos, y también, aunque en escaso número, en contextos 


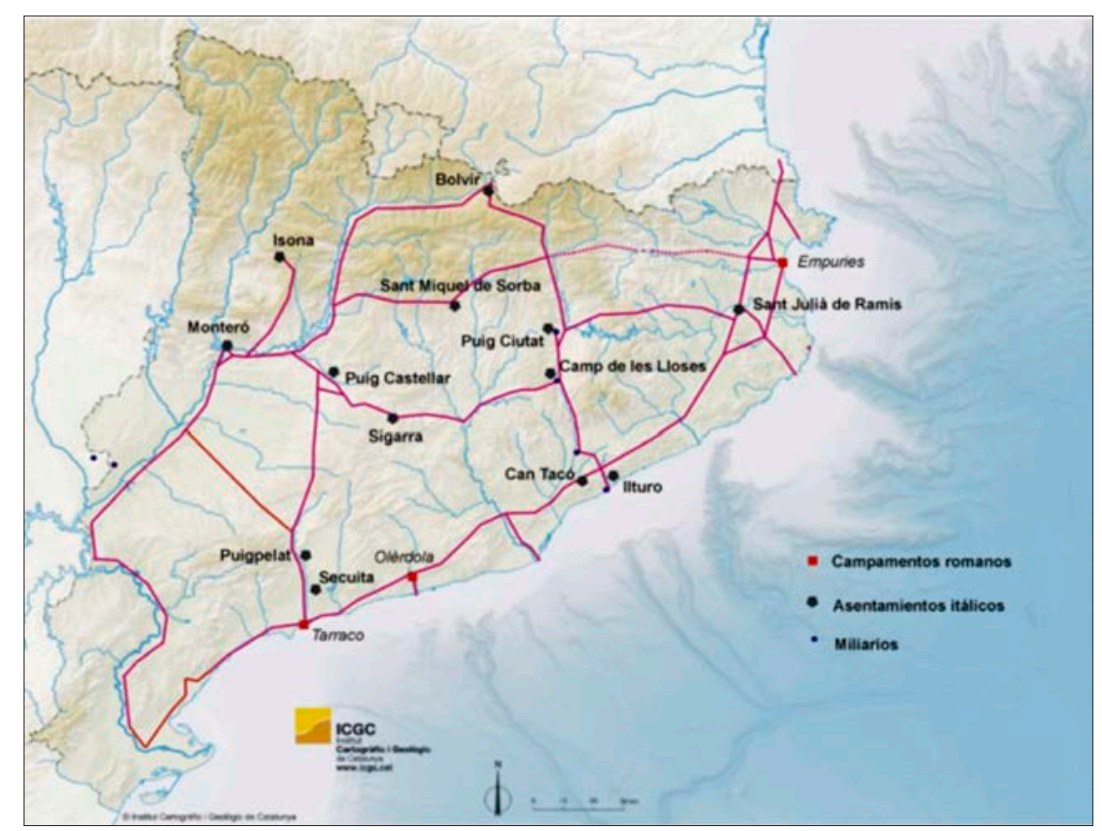

Fig. 11: Mapa de yacimientos romanos y posibles vías republicanas del NE (150-50 a.C.).

romanos republicanos. Sabemos por las fuentes que tanto Cartago como la Numidia contribuían con hombres y animales a las guerras celtíberas, y tal vez también con aportaciones de aceite. De todas formas, la cantidad de ánforas tripolitanas antiguas es reducido y se concentra sobre todo en el levante peninsular y la Ulterior (Mateo 2012).

Es evidente que no podemos utilizar solamente la distribución de ánforas brindisinas como parámetro exclusivo para medir el impacto de la intervención romana en el territorio peninsular, pues existen otras evidencias más representativas, pero creemos que las ánforas brindisinas abren una nueva vía de investigación (otra más) que nos permitirá avanzar en el conocimiento de este proceso, tanto en la costa como en el interior, durante el período comprendido entre el 150-75 a.C. A la vista del mapa de distribución observamos una mayor concentración de puntos en las áreas litorales, sobre todo junto a los puertos principales, a los que se sumarían algunas de las antiguas factorías púnicas meridionales (p.e. Gadir, Carteia, Malaca), con vínculos comerciales directos con Roma. Otros centros destacados son las zonas mineras, explotadas desde un primer momento por itálicos, como la propia Cartago Nova o las zonas mineras de La Unión y La Loba (Benquet y Olmer 2002); así como otros centros romanos del interior de tipologías variadas, como son campamentos militares, fortines o castella que pasaremos a desarrollar a continuación. Las ánforas brindisinas pues podrían estar indicando las rutas de penetración romana hacia el interior y por tanto localizar mejor las viae militariae, unas infraestructuras que después muchas de las cuales se convertirán en vías civiles a partir del s. I a.C.

Hace unos años se realizó un estudio sobre el trazado de las vías romanas del sector NE de la península Ibérica (De Soto 2010), en este trabajo proponían cronologías muy tempranas para algunos tramos (fig. 11); algunas de las dataciones se establecieron a partir de tres miliarios del procónsul Manius Sergius, localizados en Santa Eulàlia de Ronçana (Vallès Oriental), Tona (Osona) y Santa Eulàlia de Riuprimer (Osona) fechables entre el 120-110 a.C. Cabe recordar que los miliarios no aparecen en el mundo romano de forma generalizada hasta el 123 a.C. ${ }^{10}$, o sea que vías anteriores solo podrían fecharse en función de los asentamientos y materiales asociados. Para las legiones romanas las viae son una infraestructura necesaria puesto que permiten desplazarse de forma rápida hasta las zonas en conflicto y a su vez aseguran la llegada regular de provisiones desde los puertos y campamentos de invierno (castra hibernia). Mantener estos corredores accesibles era de vital importancia para la supervivencia y logística de los ejércitos romanos en campaña. Como se muestra en la fig. 11, muchos de los establecimientos militares itálicos, todos con presencia de ánforas brindisinas, se sitúan junto a las posibles viae militariae. Las rutas terrestres propuestas nacen de los principales puertos 
Fig. 12: Muestra de algunos bordes de Giancola 2 (Apani I) halladas en Puig Castellar (Biosca).

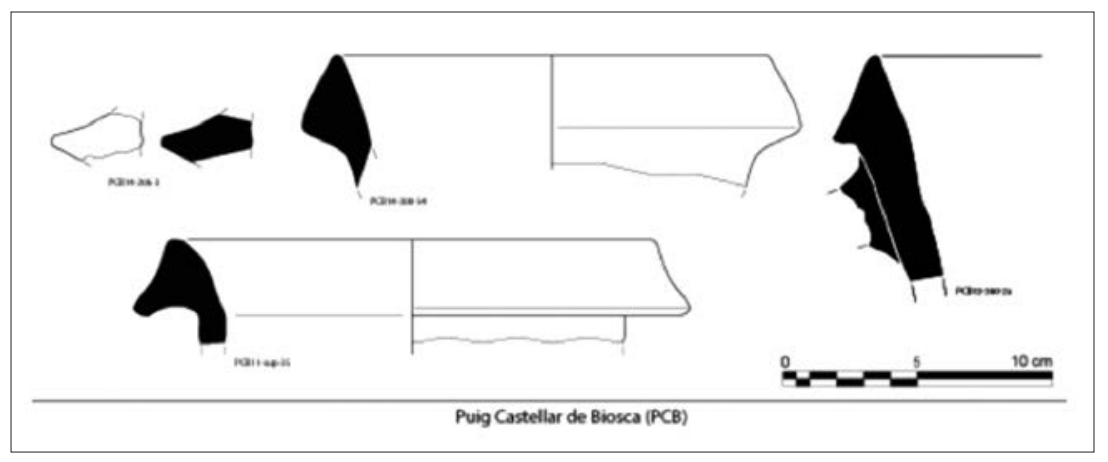

militares del NE, Empúries yTarraco, aunque a lo largo del s. II a.C. será el puerto de Tarraco el que irá adquiriendo más importancia en detrimento del anterior. Aún así, paralelo a la costa, se localizaba el principal eje de comunicación terrestre, la Via Heraklea, que llegaría hasta Gades y que más tarde recibiría el nombre de Via Augusta; siendo el emplazamiento de Sant Julià de Ramis un importante enclave militar para el control en esta ruta del interior, cercano a Empúries. Tarraco constituye una pieza clave en el entramado viario, desde este enclave portuario y militar suponemos se iniciaría otra vía que se adentraba hacía el interior en dirección a Iesso e Ilerda. Otro punto de llegada de productos itálicos creemos que sería Ilturo (Cabrera de Mar), situado al pie del poblado ibérico de Burriac en la costa central, por su cultura material, urbanismo y arquitectura se trata de un asentamiento urbano de marcado carácter itálico, fundado en la primera mitad del s. II a.C. (García Roselló et al. 2000); en este caso se trataría de un centro administrativo aunque sin una presencia militar reconocible, su ubicación equidistante en $100 \mathrm{~km}$. de Empúries y Tarraco a su vez facilitaría un acceso rápido hacia el corredor interior del Vallès (Via Heraklea) desde la costa.

En el punto donde esta vía procedente de la costa se cruza con la Heraklea se encuentra el yacimiento de Can Tacó (Montmeló) (Rodrigo et al. 2014), otro establecimiento romano de carácter administrativo con un extraordinario control visual del territorio circundante, que a partir de las evidencias de sellos en ánforas rodias y tripolitanas se puede fechar entre el 160-75 a.C. (Carreras et al. 2015). Asimismo se han documentado varias ánforas brindisinas entre las que se distinguen al menos dos formas: Giancola 2 y Giancola 5. En relación con esta misma vía que desde Ilturo penetraba hacía el interior se reconocen al menos tres miliarios de M. Sergius (120-110 a.C.), su recorrido estaba flanqueado por establecimientos republicanos con ánforas brindisinas, como los de Can Rossell (Llinars), Caseta de Fugurull (Manlleu) y El Camp de les Lloses (Tona).El yacimiento de El Camp de les Llosses muestra una cronología inicial de último cuarto de s. II a.C. y perdura hasta el s. I a.C.; desde la zona de Camp de les Lloses resulta plausible plantear la existencia de otra vía transversal hacia el $\mathrm{O}$ donde encontraríamos otros enclaves republicanos de importancia como son: Sigarra (Els Prats del Rei), un establecimiento seguramente militar de finales del II a.C. con presencia de ánforas brindisinas; el yacimiento de Puig Castellar de Biosca, un extenso establecimiento fortificado en altura para el control territorial de la vía del valle del río Llobregós; y Monteró (Camarasa), otro castellum romano en altura con una cronología inicial del 125 a.C. que controla un vado del río Segre (Sicoris flumen) con presencia también de material brindisino.

La ruta seguiría su recorrido en dirección $\mathrm{O}$, encontrando otros enclaves como Gebut o Ilerda, yacimientos donde también se han documentado las marcas tempranas de C.ANINI. Esta ruta se debería asociar a su vez con los miliarios republicanos de Q.Fabius Labeo (procónsul del 118-114 a.C.) encontrados en Massalcoreig (Lérida) y el de Torrente de Cinca (Huesca). Otro dato a favor de la existencia de esta ruta transversal y vinculada a ella sería la ciudad romana de Iesso (Guissona), cuya cronología fundacional se sitúa entre el 120-100 a.C., sus niveles fundacionales aportan un buen conjunto de ánforas brindisinas (Guitart et al. 1998, 43-45). En el conjunto brindisino de Iesso encontramos la marca APOLLONI asociada a un titulus pictus C.HE..., que por contexto podemos situar entre el 120-100 a.C., Manacorda y Pallechi fechan la marca VEHILI entre 100-75 a.C.

$\mathrm{Al}$ pie de los Pirineos encontramos también algunos establecimientos romano-republicanos con presencia de ánforas brindisinas como son la ciudad romana de Aeso (Isona) y El Castellot de Bolvir (Cerdaña) este último en 


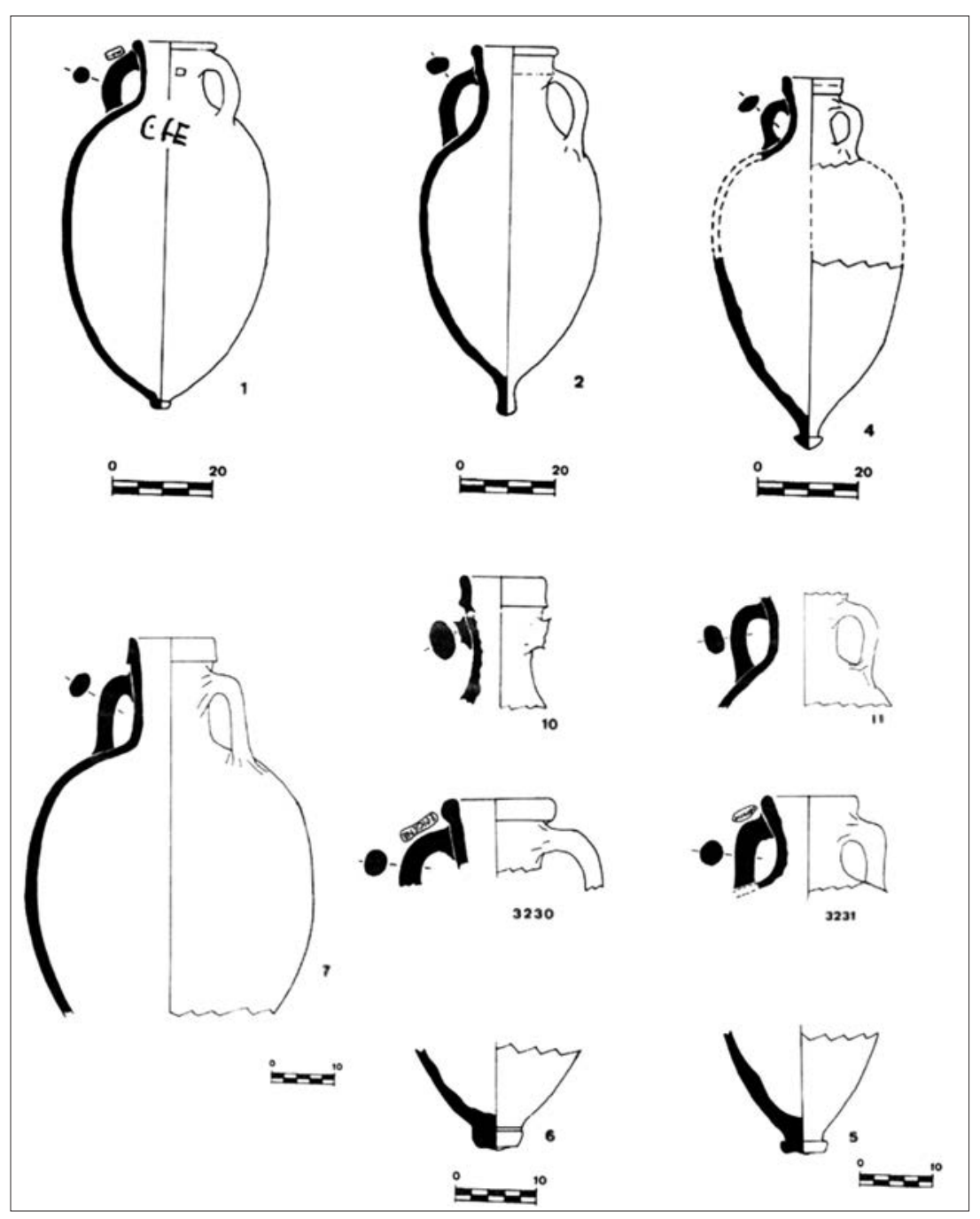

Fig. 13: Ánforas brindisinas de las fosas de Guissona (Guitart et al. 1998 43-45): 1. Giancola 5; 2. Giancola $3 ; 4$. Giancola $1 \mathrm{C} ; 7$. Giancola 1D; 10. Giancola 1C; 11. Giancola 1?; 3230. Giancola 5; 3231. Giancola 5; 6. Giancola 3-5; 5. Giancola 3-5.

la vía natural del Segre que se adentra en Francia, donde también encontramos algunos hallazgos de ánforas brindisinas. Otro yacimiento interesante es Sant Miquel de Sorba, en la zona montañosa del Berguedà, se trata de un enclave de origen ibérico que tiene una fase romano-republicana muy destacada con una potente muralla y torres; recientes excavaciones han aportado un importante conjunto anfórico donde se identifican un buen número de ánforas brindisinas de los tipos Giancola 2 y 5 . El hallazgo de un tramo de vía en el curso alto del valle del Llobregat, posiblemente republicana, en Sant Bartomeu de Grau (Oristà) (Cascante 2008) sugiere la existencia de otra ruta que justificaría el emplazamiento romano de Sant Miquel de Sorba.
Otro corredor natural de acceso hacía el interior con presencia de ánforas brindisinas es el curso bajo del valle del río Llobregat, con ejemplares conocidos en Sant Feliu de Llobregat, Sant Boi i Cornellà. Siguiendo el trazado de la Via Heraklea a su paso por el Penedès se documentan brindisinas en El Bosquet i en la fortaleza de Olérdola, un campamento militar romano con potentes murallas, situado en un punto estratégico para el control de la Via Heraklea (Molist 2014), en esta fortificación se ha documentado también un sello de ánfora brindisina, C. HELVIC.F. (Ros 2007), un personaje del cual se va a tratar más adelante. Otra evidencia se encuentra en el castellum romano de Puigpelat (Valls) en este yacimiento se documentaron 3 bordes de Giancola 2 (Apani I). Recientemente, 
Fig. 14: Tituli picti CHE 1: Iesso junto el sello APOLLONI, 2: Gebut (Moran 2010) y el sello 3: C.HELVI.C.F. de Olérdola (Ros 2007).

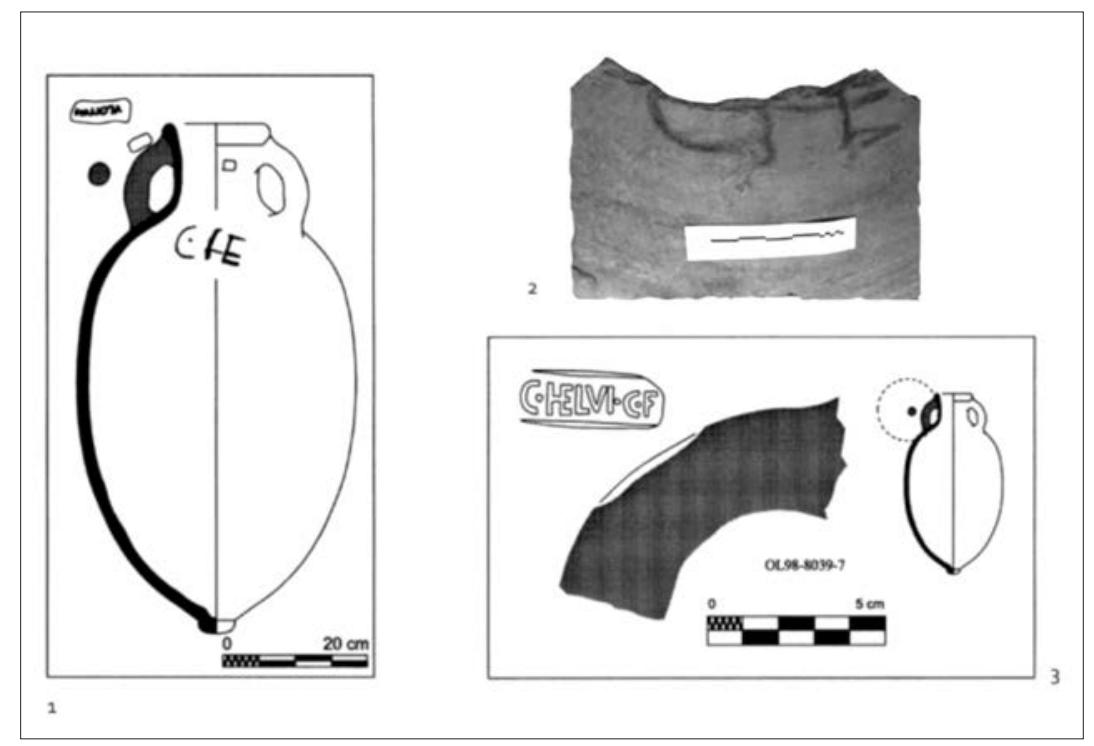

se ha excavado otra fortificación romana republicana en La Secuita, próxima al embalse del río Gaià (Tarragona), con la presencia de Giancola 5 con la marca C.ANINI. Ambos yacimientos se encontrarían franqueando la vía que iría desde Tarraco hacia Ilerda.

Todas las vías y rutas que acabamos de describir, documentadas en la zona de la actual Cataluña, se dirigen en último término hacia el valle del Ebro que constituye la ruta natural de acceso hacia el interior de la Península, una región estratégica en el proceso de conquista de la Citerior a mediados de s. II a.C.; cabe recordar que el valle del Ebro constituye la retaguardia logística más próxima al teatro de operaciones de las guerras numantinas y uno de los destinos finales de muchas de las ánforas. Como ya había observado M. Beltrán, en los yacimientos del valle del Ebro se documenta una amplia representación de ánforas adriáticas, tanto vinarias (Lamboglia 2), como brinsidinas en cronologías de finales del s. II a.C. como principios del I a.C., en yacimientos tan destacados como Azaila, Borja, Botorrita, Celsa, Caminreal, Fuentes del Ebro o Monzón (Beltrán 1980; 1983). En el cerco de Numancia las evidencias de estas ánforas resulta más compleja; Sanmartí en su estudio anfórico del campamento de Peña Redonda (Garray) no incluía más que formas greco-itálicas, Dressel 1A o CCNN, pero por la descripción que formula de las pastas cerámicas E y F, tal vez pueda tratarse de envases adriáticos (Sanmartí 1985). En un reciente trabajo (Morales 2000 fig.7, 4) sobre el asedio de Escipión en Numancia, se recogen materiales de prospección procedentes del fuerte de Peña del Judío, donde vemos una forma con asas circulares que parece corresponder a una Giancola 5. Por último, el campamento de Renieblas proporciona otro tipo de envases olearios itálicos: las ovoides del Lacio (Sanmartí 1992).

En la zona levantina la presencia de las ánforas brindisinas se documenta tanto en los contextos fundacionales de Valentia (138 a.C.) como en el momento de la destrucción sertoriana (75 a.C.), sin embargo las cantidades no son muy significativas (Ribera 2013), puesto que suelen ir acompañadas de otra ánfora olearia, la tripolitana antigua (Mateo 2012). El ejemplo de Valentia muestra un patrón en la proporción de ánforas brindisinas que se puede hacer extensivo a todo el Levante, tal como ocurre en yacimientos próximos a la costa como L'Alcúdia, Loma de Herrerías, La Unión, L'Horta Seca, Torre de la Sal o Vilajoyosa. Por supuesto, también están documentadas ánforas brindisinas en yacimientos de las Islas Baleares, hasta donde hemos podido conocer encontramos ejemplares en Son Fornés y Son Espases (Palma), y seguramente no son los únicos, ya que en la ruta marítima hacia Hispania las islas Baleares serían escala obligada sobretodo en la ruta hacia el puerto de Cartago Nova.

Si bien el número de ejemplares brindisinos documentado en el Levante peninsular es limitado, en lo que se refiere a la Provincia Ulterior resulta aún más escaso por ahora; la presencia de ánforas brindisinas se reduce a los yacimientos de Baelo, Carteia, Cerro de Montecristo, Chipiona, Gadir, La Algaida, Lacipo, La Loba, 
César Carreras Monfort, Albert Martín Menéndez, Joaquim Pera Isern, Esther Rodrigo Requena

\begin{tabular}{|c|c|c|c|c|c|c|c|c|c|c|c|}
\hline$\left(\begin{array}{l}2 \\
0 \\
5 \\
3 \\
0\end{array}\right.$ & 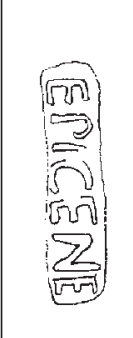 & $\frac{5}{9}$ & 2 & 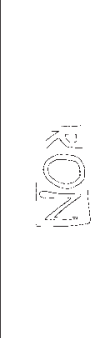 & $\frac{2 n}{\frac{2 n}{20}}$ & $\widehat{0}$ & 3 & $\sum_{\infty}^{\infty}$ & $\begin{array}{l}2 \\
2 \\
0 \\
0 \\
0 \\
0 \\
0\end{array}$ & 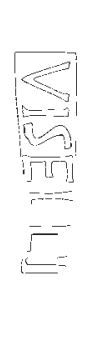 & \\
\hline 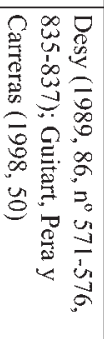 & 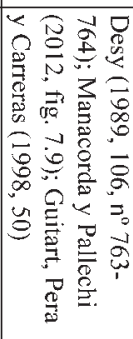 & 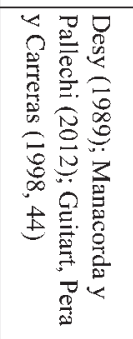 & 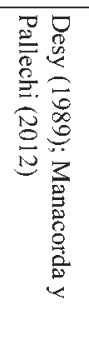 & 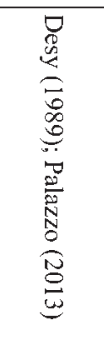 & 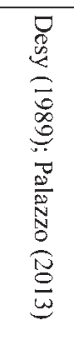 & 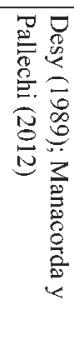 & 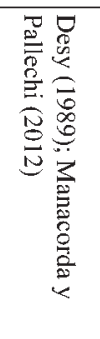 & 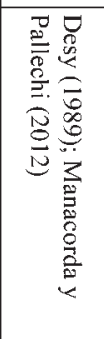 & 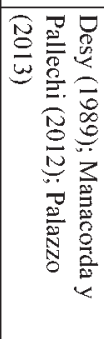 & 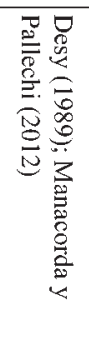 & \\
\hline & 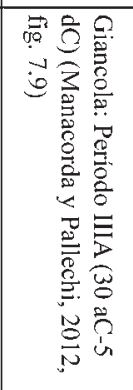 & 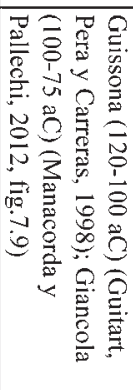 & & 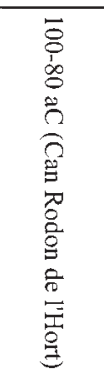 & & & 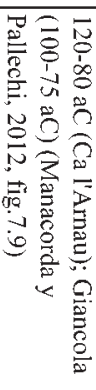 & 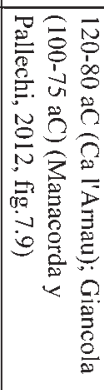 & 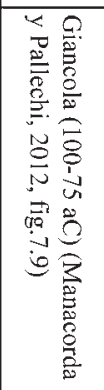 & 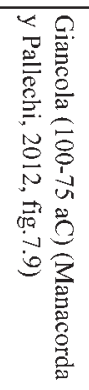 & \\
\hline $\begin{array}{l}\text { Q } \\
\text { E. } \\
0.0 \\
\text { : }\end{array}$ & 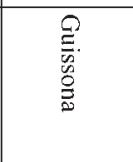 & 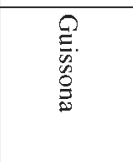 & 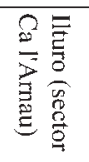 & 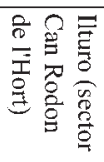 & 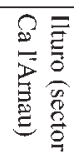 & 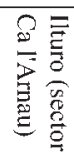 & 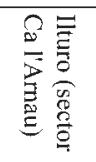 & 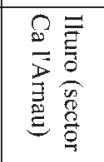 & 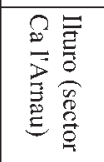 & 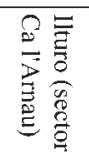 & 5 \\
\hline 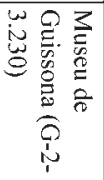 & 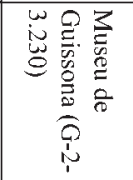 & 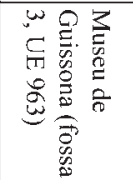 & 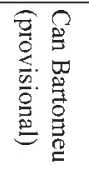 & 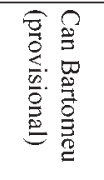 & 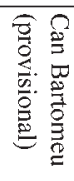 & 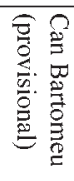 & 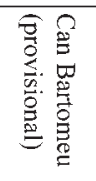 & 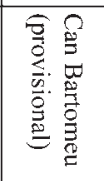 & 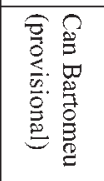 & 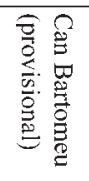 & 6 \\
\hline 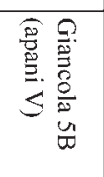 & 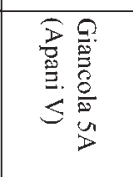 & 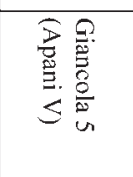 & 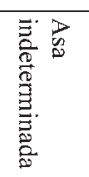 & 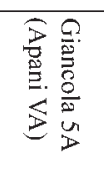 & 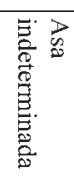 & 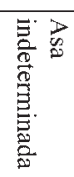 & 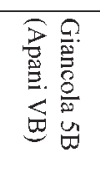 & 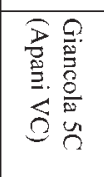 & 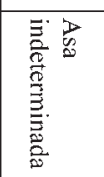 & 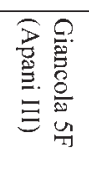 & $\underline{z}$ \\
\hline 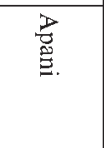 & 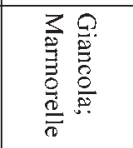 & 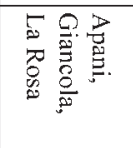 & $\begin{array}{l}9 \\
\frac{9}{20} \\
\frac{2}{20}\end{array}$ & 慝 & 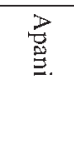 & 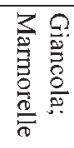 & 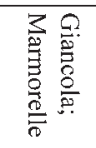 & 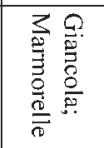 & 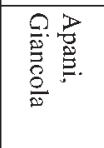 & 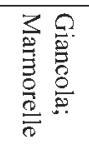 & 7 \\
\hline 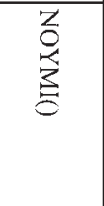 & $\begin{array}{l}\text { 署 } \\
\frac{9}{9} \\
\frac{1}{2} \\
\text { 恶 }\end{array}$ & 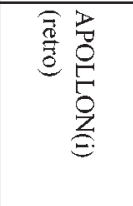 & $\begin{array}{l}\text { 党 } \\
\text { 䎡 } \\
\text { 系 }\end{array}$ & 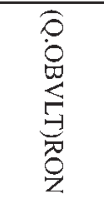 & $\stackrel{4}{\pi}$ & 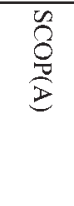 & 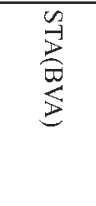 & $\sum_{j}^{\infty}$ & $\begin{array}{l}\text { Z } \\
0 \\
\vdots \\
Z\end{array}$ & 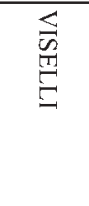 & \\
\hline
\end{tabular}


Málaga y Sevilla (Mateo 2012). En un reciente trabajo (Bernal et al. 2013) en el que se estudian las ánforas republicanas, sobre todo vinarias, encontramos alguna referencia a brindisinas, en La Loba (Benquer y Olmer, 2002) y en Sevilla (patio de banderas del Alcázar). A partir de los sellos documentados hasta ahora, las importaciones en la Ulterior corresponderían al período 125-75 a.C. con las marcas VEHILI, APOLLON, SCOPAS o VISELLI. Resulta paradójico este escaso número de ánforas brindisinas, puesto que son los modelos de envase que pretendidamente copiarán los alfareros béticos al realizar sus formas de envase característico como son: las Ovoides 1 de la costa o las Ovoides 4 del valle del Guadalquivir, que iniciarán su producción en fechas ligeramente posteriores, entre el 80-70 a.C. Estos nuevos envases que parecen contener aceite son los predecesores de formas como la Haltern 70 o la Oberaden 83 del Guadalquivir (García Vargas et al. 2011). Tal vez las guerras sertorianas frenaron temporalmente las importaciones regulares olearias itálicas y favorecieron una producción local propia.

Para el caso de la Lusitania y la costa Atlántica del NO, los hallazgos de brindisinas son aún menores, se documentan tan sólo en yacimientos costeros (Mateo 2012) y en el valle del Tajo (Pimenta et al. 2012). Aunque cabe destacar que algunos de estos establecimientos tienen carácter militar (Alto do Cacos, Cáceres el Viejo) o itálico (Santarem u Olisipo), junto con puntos como Santa Tegra o Castro de Alobre, vinculados a los contactos expedicionarios de Décimo Junio Bruto (137-136 a.C.) o a las posteriores campañas de Julio César (61-60 a.C.).

\section{CONCLUSIONES}

A partir de los sellos podemos establecer que es entre el 125-75 a.C. cuando encontramos un mayor número de marcas brindisinas documentadas en Hispania. Las más antiguas entre 125-100 a.C. se encuentran en L'Alcúdia (SOTERICOS), Horta Seca (FCAN), Sagunto (FCAN) y Sant Feliu (DAMA). La marca más común es APOLLONI documentada en Azaila, Cabezo Agudo, Cabrera de Mar, El Bosquet, Empúries, Hispalis, La Loba, Missatge de Claravalls, Sant Boi, Tarraco, Iesso y Valentia . Tal y como hemos podido constatar en nuestro análisis, todo parece indicar que el consumo de aceite itálico, transportado en ánforas brindisinas, tuvo un comercio limitado en cuanto a su volumen en Hispania ${ }^{11}$, por tanto no creemos que sea representativo de un aprovisionamiento regular y generalizado para el ejército; parece más bien un producto destinado al consumo de una minoría itálica, con una preferencia por los vinos adriáticos (Giancola 1 y Lamboglia 2) y el aceite brindisino. Aunque cabe recordar que el aceite de oliva consumido en la Península en época republicana no era solo de origen itálico, encontramos también envases olearios africanos desde la primera mitad del s. II a.C, como las ánforas Tripolitanas antiguas (Pascual y Ribera 2002; Mateo 2012). La difusión de las ánforas procedentes del N de África en la Península es muy similar a las ánforas brindisinas, las encontramos concentradas en la zona levantina, NE peninsular y valle del Ebro. Hasta el reciente trabajo de Mateo (Mateo 2012), apenas se conocían en la Ulterior y zona lusitana, pero ahora las tenemos documentadas en los puertos mediterráneos y atlánticos, en la zona del Algarve y en el valle del Tajo, aunque siempre en menor proporción respecto a las ánforas vinarias comunes del período y acompañadas en algunos contextos por ánforas rodias.

Tanto el aceite brindisino como el tripolitano lo encontramos en asentamientos de marcado carácter itálico, algunos relacionados con una función militar, por lo que deducimos que este fenómeno de distribución obedece a una pauta de consumo propiciada por personal itálico, y por tanto puede ser tomado a modo de factor diferenciador de tipo étnico-social frente a las prácticas de consumo propias de las poblaciones locales. Como habíamos indicado anteriormente se conocen pocas evidencias de instalaciones olearias en centros ibéricos por lo que se deduce que el aceite, en general, no era un producto habitual de sus dietas. Nuestro planteamiento se resume en considerar que al igual que existen vinos de calidad importados y consumidos por algunas élites, la llegada de aceite brindisino puede obedecer a un fenómeno semejante. En este marco, el aceite se podría considerar como un producto elitista, consumido mayoritariamente por itálicos con un mayor poder adquisitivo (oficiales, colonos o altos funcionarios), o bien simplemente con acceso a estos suministros en caso de ser militares; la existencia de este mercado pudo incentivar a los comerciantes itálicos a incorporar estas ánforas en sus cargamentos para dar satisfacción a estas demandas minoritarias. Uno de estos comerciantes debió ser C(aius) $H E$ () que aparece en un titulus pictus rotulado sobre una de las ánforas procedente de Iesso, fechada por contexto entre 120-100 a.C. (Guitart et al. 1998: 46-48). Recientemente se ha publicado otro titulus pictus procedente de una ánfora brindisina hallada en el yacimiento leridano de Gebut (Morán 2010: fig.1.7) con las mismas letras C(aius) $H E$ ( ). 
La interpretación del posible nomen del personaje estaba abierta: se había sugerido que el nombre incompleto se podía referir a Caius Herennius, no obstante, el hallazgo reciente de una marca C.HELVI.C.F. descubierta en Olérdola (Ros 2007) plantea la posibilidad de que los dos tituli de Iesso y Gebut pertenezcan a la familia de comerciantes de los Helvii.

La familia de los Helvii era de origen volsco, relacionada con la ciudad de Capua; Un tal M. Helvius fue praetor en la Ulterior en el 197 a.C., siendo esta una primera vinculación de la familia con Hispania. Este mismo personaje será triunviro en la colonia apula de Sipontum. En la primera mitad del s. I a.C. la familia de los Helvii está vinculada al comercio con Oriente, testimoniada por inscripciones en Delos, en Mileto y en Kos (Hatzfeld 1912: 42; 1919: 100-101). No resultaría extraño que esta familia también participase en el aprovisionamiento de aceite brindisino a la Península, bien en su papel de productores con la marca C.HELVI.C.F., que todavía no se ha podido fechar, o bien como negotiatores a partir de los tituli de Iesso y Gebut, estos con una datación de finales del II a.C. Desconocemos hasta qué punto el apoyo silano a la colonia inmune de Brindisium, a partir del año 83 a.C., y la consiguiente promoción comercial de su puerto con Oriente pudieron influir en la distribución de sus ánforas en la península Ibérica; pero creemos que el conflicto sertoriano en Hispania debió de producir cambios en los circuitos comerciales y de aprovisionamiento de los ejércitos enfrentados. No podemos asegurar que las dificultades de aprovisionamiento exterior, en caso de existir, sean uno de los motivos que expliquen el desarrollo de las producciones locales, como en el caso de las ánforas ovoides hispanas, documentadas hacia el año 80 a.C.: por ejemplo, las Ovoide 4 del valle del Guadalquivir con posible aceite bético se empiezan a distribuir fuera de la Ulterior (García Vargas et al. 2011), ya que se han encontrado ejemplares en Can Tacó (Montmeló) o Santarem; o bien las Ovoide 1 gaditanas ${ }^{12}$, que surgen un poco después (70 a.C.) parecen comercializarse sobre todo hacía el Atlántico.

\section{NOTAS}

1. Este estudio ha sido realizado en el marco de los proyectos "Arqueología de la conquista e implantación romana en Hispania. Estrategias y modelos de implantación territorial en el NE de la Provincia Citerior (s. II-I a.C.)" HAR2012 37003 C03-01 y HAR2015-64601-C3-1-R. con financiación del MINECO y de la Universidad Autónoma de Barcelona.
2. Todas ellas comparten la presencia de rocas calcáreas. Los grupos I y II del taller de Giancola incluyen también la presencia de augita, procedente de la zona volcánica próxima de Vulture (Apeninos), cuyo sedimento llegaría arrastrado por vía fluvial; por el contrario el grupo III de Marmorelle no observa la presencia de augita. Otra característica diferencial es la abundante presencia de microfauna en los grupos II y III. Conviene recordar que aún quedan por caracterizar las pastas de algunos talleres de la zona de Brindisi, como por ejemplo el taller de La Rosa (al sur de Brindisi) y sobre todo, el de Cimentero Vecchio (próximo a Apani y a Brindisi).

3. Algunas de ellas con diferentes cantidades de augita, cristales volcánicos o microfósiles, vinculadas a la marca Betilienus, seguramente de La Rosa; asimismo también se han documentado otras pastas cerámicas dos de ellas asociadas a la marca Visellius, marca que se vincula a los talleres de Giancola y Marmorelle.

4. Existe otro pecio, Pla de Tudela (Cadaqués), junto con ánforas Dressel 1A producidas en el algún centro del Adriático (Piceno o Emilia-Romagna) con una pasta similar a las Lamboglia 2 (Martín, inédito), un tipo que también se ha documentado en el yacimiento de Puig Castellar (Biosca). A nivel macroscópico se parece a la pasta cerámica procedente de los talleres de Rimini (Stoppioni 2013).

5. En la mayor parte de la bibliografía dicho asentamiento (Ilturo) ha sido dado a conocer con los diversos nombres de las parcelas donde se han realizado los trabajos de excavación, como es el caso de Ca l'Arnau, Can Mateu, Can Benet, Can Rodon de l'Hort y algunos más.

6. Esta cifra incluye todos los fragmentos de boca, asas y pivote, excluyendo los fragmentos sin forma.

7. Recientemente se ha discutido la denominación de esta tipología, que en vez de Tripolitana antigua se debería llamar Africana antigua, ya que su área de producción supera la región de la Tripolitania e incluiría la zona de Cartago (Capelli y Contino 2013). Para evitar confusiones mantenemos la denominación más corriente de Tripolitana antigua.

8. Es lógico pensar que sólo personal itálico podría valorar el coste que suponía importar desde el Adriático un ánfora con un aceite de gran calidad. Difícilmente este tipo de importaciones serían valoradas por las poblaciones indígenas de la Península. Un razonamiento similar se ha empleado para explicar la distribución de ánforas olearias en otras provincias del Imperio en provincias como Germania o Britannia (Carreras y Funari 1998), aunque en éstas es aún más claro porque no son productoras de aceite.

9. Existen yacimientos como Saus (Girona) (Casas 2010) con prensas ibéricas que por la forma parece producían aceite datadas en el s. V a.C. Otro ejemplo sería la prensa de Els Estinclells (Verdú) (Asensio et al. 2010) conservada in situ o la de la Font de la Canya (Avinyonet del Penedés), si bien entre los restos carpológicos se han encontrado uva, y algunos casos aceitunas (López 2006). Tal vez las prensas se utilizaban indistintamente, como en la actualidad, para prensar vino y aceite.

10. Hasta C. Sempronio Graco no hay constancia de miliarios en las vías, será a partir de la lex Semproniana (Plutarco, C.Graco, VII.1-4), de los años 123 a.C., aunque tal vez algunas vías existían antes de ser marcadas con miliarios.

11. A pesar de disponer de pocos conjuntos cuantificados, a nivel porcentual son ánforas que no acostumbran a alcanzar porcentajes más allá del 5\% en el NMI, con algunas excepciones destacadas en Tarraco y Iesso para fases muy concretas (Díaz 2013; Guitart, Pera y Carreras 1998).

12. Comentario personal de E.García Vargas sobre la presencia de Ovoides 1 de pasta gaditana, que nosotros documentamos en el yacimiento de Can Tacó. 


\section{BIBLIOGRAFÍA}

ALMAGRO, M. (1952): Las inscripciones ampuritanas griegas, ibéricas y latinas, Barcelona

ASENSIO, D. (2010): El comercio de ánforas itálicas en la Península Ibérica entre los siglos IV y I a.C. y la problemática en torno a las modalidades de producción y distribución, XVII International Congress of Classical Archaeology, Roma 22-26 Sept. 2008, Bolletino d'Archeologia online, 23-41.

ALONSO CAMPOY, D.; PINEDO, J. (2007): Notas sobre las ánforas adriáticas del pecio Escombreras 2 (Cartagena), Comercio, redistribución y fondeaderos. La navegación a vela en el Mediterráneo (Gandia, 2006), Valencia, 221-229.

AQUILUÉ, X.; CASTANYER. P.; SANTOS, M.; TREMOLEDA, J. (2002): El campo de silos del área central de la ciudad romana de Empúries, Rómula 1, 9-38.

ASENSIO, D.; CARDONA, R.; FERRER, C.; MORER, J.; POU, J.; SAULA, O.; GARCÍA, C. (2010 ): Una almàssera del segle III aC dins del nucli ibèric dels Estinclells (Verdú, Urgell), Urtx 24, 55-76.

ÀTICS (2003): Memòria dels treballs arqueològicsa la Via Romana de Parpers, Annex I, Ajuntament d'Argentona.

BELTRÁN, M. (1980): El comercio del aceite en el valle del Ebro a finales de la República y comienzos del Imperio romano, Producción y comercio del aceite en la Antigüedad: Primer Congreso Internacional, Madrid, 187-224

BELTRÁN, M. (1983): El aceite en Hispania a través de las ánforas: la concurrencia del aceite itálico y africano Producción y comercio del aceite en la Antigüedad: Segundo Congreso Internacional, Madrid, 515-549.

BENQUET, L.; OLMER, F. (2002): Les amphores, La Loba (Fuenteobejuna, Corduue, Espagne). La mine et lavillage minier antiques (J. M.Blázquez, C. Domergue et al., eds.), Bordeaux, 295-331.

BERNAL, D.; GARCÍA VARGAS, E.; SAEZ, A. (2013): Ánforas itálicas en la Hispania meridional, Immensa aequora workshop (G.Olcese, ed.), Roma, 352-372

BERNI, P. (1996): Instrumentum domesticum romà del Museu Episcopal de Vic. La col·lecció de segells d'àmfora, tegula i morter, Pyrenae 27, 311-326.

BEZECZKY, T. (2013): The amphorae of Roman Ephesus, Viena.

CAPELLI, C.; CONTINO, A. (2013): Amphores tripolitaines anciennes ou amphores ou africaines anciennes?, Antiquités Africaines 49, 199-210.

CARRERAS, C.; FUNARI, P. P. A. (1998): Britannia y el Mediterráneo. Estudios sobre el comercio de aceite bético y africano en Britannia, Instrumenta vol. 5, Barcelona.

CARRERAS, C.; RODRIGO, E.; PORCHEDDU, V. (2015): Marques africanes i ròdies de Can Tacó (Montmeló), Pyrenae 46-2, 1-17.

CASCANTE, P. (2008): Memòria de la intervenció arqueológica al nou vial de la carretera C-154 fins a l'Eix Transversal. Sant Bartomeu del Grau - Oristà - Muntanyola - Olost (Osona), Servei d'Arqueologia de la Generalitat
CASAS, J. (2010): Prensas para la elaboración de aceite en el establecimiento rural ibérico de Saus (Gerona). Notas sobre la explotación del campo en el territorio de Emporion, AEspA $83,67-84$.

CIPRIANO, M. T.; CARRÉ, M. B. (1989): Production et typologie des amphores sur la côte adriatique de l'Italie, En Amphores romaines et histoire économique. Dix ans de recherche, Siena (1986), CEFR 114, Roma, 67-104.

COMPATAGNELO-SOUSSIGNAN, R. (1999): Sur les rutes d'Hannibal. Paysatges de Campania et Apulie. Besançon.

DE SOTO, P. (2010): Anàlisi de la xarxa de comunicacions $i$ del transport a la Catalunya romana: Estudis de distribució $i$ mobilitat. Tesis inédita - Universitat Autónoma de Barcelona.

DESY, Ph. (1989): Les timbres amphoriques de l'Apulie républicaine, BAR Int.Ser. 554, Oxford.

DESY, PH.; DE PAEPE, P. (1990): Torre San Giovanni (Ugento): les amphores commerciales hellénistiques et républicaines, Studi di antichità 6, 187-234.

DÍAZ GARCÍA, M. (2009): El castellum de Puigpelat, Biblioteca Tàrraco d'Arqueologia 5, Tarragona.

DÍAZ GARCÍA, M. (2013): Conjunts ceràmics dels segles II-I aC a Tarragona. Producció, comerç i consum a la Tarraco republicana, Tesis inèdita, Universitat Rovira i Virgili.

GARCÍA ROSELLÓ, J.; MARTIN, A.; CELA, X. (2000): Nuevas aportaciones sobre la romanización en el territorio de Iluro (Hispania Tarraconensis), Empúries 52, 29-54.

GARCÍA VARGAS, E.; DE ALMEIDA, R.; GONZÁLEZ, H. (2011): Los tipos anfóricos del Guadalquivir en el marco de los envases hispanos del siglo I aC. Un universo heterogéneo entre la imitación y la estandarización, SPAL 20, 185-283.

DOI: https://doi.org/10.12795/spal.2011.i20.12

GUITART, J.; PERA, J.; CARRERAS, C. (1998): La presència de vi itàlic a les fundacions urbanes del principi del segle I aC a l'interior de Catalunya: l'exemple de Iesso, II Col·loqui Internacional d'Arqueologia Romana. El vi a l'antiguitat, Badalona, 39-65.

HATZFELD, J. (1912): Les italiens résidant a Délos, Bulletin de Correspondance Hellénique 36.1, 5-218.

HATZFELD, J. (1919): Les trafiquans italiens dans l'Orient Hellénique, Paris.

LÓPEZ, D. (2006): L'agricultura protohistòrica des d'una perspectiva arqueobotànica (llavors i fruits). Estudi de l'assentament del Turó de la Font de la Canya (Avinyonet del Penedès, Alt Penedès), Treball del Diploma d'Estudis Avançats (D. E. A.). Universitat de Barcelona, 2006

LOUGHTON, M. E. (2003): The distribution of Republican amphorae in France, Oxford Journal of Archaeology 22 (2), 177-207.

MANACORDA, D. (1989): Le anfore dell'Italia republicana: aspetti economici e sociali, Amphores romaines et histoire économique. Dix ans de recherche (Siena 1986), Roma, 443-467. 
MANACORDA D. (1994): Produzione agricola, produzione ceramica e proprietà della terra nella Calabria romana tra Repubblica e impero, Epigrafia della produzione e della distribuzione (Roma 1992), Roma, 3-59.

MANACORDA, D.; PALLECHI, S. (2012): Le forni romane di Giancola, Bari.

MARANGIO, C. (1975): La romanizzazione dell'ager brundisinus, RicStBrindisi 8, 105-133.

MAS, J. (1985): Excavaciones en el yacimiento submarino de 'San Ferreol' (costa de Cartagena), VI Congreso Internacional de Arqueología Submarina (Cartagena 1982), Cartagena, 189-224

MÁRQUEZ, J. C.; MOLINA, J. (2005): Del Hiberus a Carthago Nova. Comercio de alimentos y epigrafía anfórica grecolatina, Instrumenta vol.18, Barcelona.

MARTÍNEZ GÁZQUEZ, J. (1992): La campaña de Catón en Hispania, Barcelona.

MATEO, D. (2012): La importación de aceite tripolitano en Hispania Ulterior durante la época tardorepublicana, Estudiar el pasado: aspectos metodológicos de la investigación en Ciencias de la Antigüedad y de la Edad Media (A.Castro et al. eds.), BAR Int. Ser. 2412, Oxford, 119-127.

MOLIST, N. (2014): La fortificación tardorrepublicana de Olérdola y el control del acceso Norte a Tarraco, Las guerras civiles romanas en Hispania. Una revisión histórica desde la Contestania (F.Sala y J.Moratalla, eds.), Alicante, 229-248.

MORALES, F. (2000): Una reinterpretación de la circunvalación escipiónica de Numancia, R.A.P. 10, 227-241.

MORÁN, M. (1997): Notas sobre epigrafía anfórica en la Catalunya interior, R.A.P. 7, 249-260.

MORÁN, M. (2010): Tres nuevos sellos de ánforas brindisinas en Ilerda y su entorno, R.A.P. 20, 195-196.

NOLLA, J. M.; PALAHÍ, L.; VIVO, J. (2010): De l'oppidum a la civitas. La romanització inicial de la Indigècia, Girona.

PAGLIARA, C. (1968): Bolli anforari inediti di Felline, SCO XVII, 227-231.

PALAZZO, P. (1988): Aspetti tipologici della produzione di anfore brindisine, I Convegno di studi sulla Puglia romana (Mesagne, 1986), Mesagne, 109-117.

PALAZZO, P. (1989): Le anfore de Apani (Brindisi), Amphores romaines et histoire économique. Dix ans de recherche (Siena 1986), CEFR 114, Roma, 548-553.

PALAZZO, P. (1992): Nuovi rinvenimenti in Località La Rosa Brindisi, Taras XII.1, 115-130.

PALAZZO, P. (1994): Brindisi. Località Marmorelle: le fornaci e i repertori anforarri, Epigrafia e territori. Politica e società, Bari, 201-225.

PALAZZO, P. (2013): Le anfore di Apani (Brindisi), Roma.

PARKER, A. J. (1992): Ancient shipwrecks. The Mediterranean and the Roman provinces, BAR Int. Ser. 580, Oxford.

PASCUAL, G.; RIBERA, A. (2012): Las ánforas tripolitanas antiguas en el contexto del Occidente Mediterráneo. Un contenedor poco conocido de la época republicana, Vivre, pro- duire et échanger: reflets méditerranéens. Mélanges offers à Bernard Liou, Archéologie et Histoire romaine 8, Montagnac, 303-318.

PATTERSON, H.; OLCESE, G. (2012): I bolli e l'archeometria, Le forni romane di Giancola (D. Manacorda, S. Pallechi, eds), Bari, 385-392.

PÉREZ BALLESTER, J.; PASCUAL, G. (2004): The Adriatic amphora type L.2 recovered from the environment of Cartagena (Murcia, Spain), Close encounters: Sea and riverborne trade, ports and hinterland. Ship construction and navigation in Antiquity, Middle Ages and in Modern times (M. Pasquinucci y T. Weski, eds.), BAR Int. Ser. 1283. Oxford, 27-37.

PIMENTA, J.; HENRIQUES, E.; MENDES, H. (2012): O Acampamento Romano do Alto dos Cacos, Almeirin.

RIBERA, A. (1995): Una peculiar fosa de fundación de Valentia, Sagvntvm-PLAV 29, 187-196.

RIBERA, A. (2013): Los pecios del litoral ibérico y la fundación $(138 \mathrm{aC})$ y destrucción de Valentia $(75 \mathrm{aC})$, Immensa aequora workshop (G.Olcese, ed.), Roma, 455-468.

RODRIGO, E.; GUTIÉRREZ, A.; ÀLVAREZ, A.; PITARCH, A.; MERCADO, M.; GUITART, J. (2013): El yacimiento de Can Tacó (Vallès Oriental, Cataluña) y el inicio de la arquitectura de tipo itálico en la península ibérica. Análisis de los materiales constructivos cerámicos (tegulae y imbrex), Actas del I Congreso Internacional sobre Estudios Cerámicos. Homenaje a la Dra. M. Vegas, Cádiz, 1572-1594.

RODRIGO, E.; CARRERAS, C.; GUITART, J.; PERA, J.(2014): La presencia romana en el NE de la provincia Citerior durante el siglo II aC. Aproximación arqueológica a partir de los yacimientos de Can Tacó (Montmeló, Barcelona) y Puig Castellar, Los paisajes agrarios de la romanización, arquitectura y explotación del territorio, Anejos del AEspA LXX, 91-209.

ROS, A. (2007): Los Helvii. Comerciantes en Occidente y Oriente durante época Bajorrepublicana, Acta XII Congressus Internationalis Epigraphiae Graecae et Latinae, Barcelona, 1247-1254.

SANMARTÍ, E. (1985): Las ánforas romanas del campamento numantino de Peña Redonda (Garray, Soria), Empúries 47, 130-161.

SANMARTÍ, E. (1992): Nouvelles données sur la chronologie du camp de Renieblas V à Numance (Soria, Castilla-León, Espagne), Documents d'Archéologie Méridionale 15, 417-430. DOI: https://doi.org/10.3406/dam.1992.1076

SANMARTÍ, J.; SANTACANA, J. (2005): Els Ibers del Nord, Barcelona.

SANTANGELO, F. (2007): Sulla, the elites and the Empire, Amsterdam.

DOI: https://doi.org/10.1163/ej.9789004163867.i-300

SINNER, A. (2013): La difusión de las emisiones ibéricas layetanas, Sagvntvm-PLAV 45, 173-194. DOI: https://doi.org/10.7203/SAGVNTVM.45.2466 
STOPPIONI, M. L. (2013): Le anfore di Rimini in età repubblicana, Immensa Aequora Workshop. Richerche archeologiche, archemetriche e informatique per la ricostruzione dell'economia e dei commerci nel bacino occidentale del Mediterraneo (G.Olcese, ed.), Roma, 265-274.

TONIOLO, A. (2000): Le anfore di Adria: IV-II a.C., Padova.

TREMOLEDA, J.; CASTANYER, P. (2013): Las ánforas republicanas itálicas de Catalunya (siglos III-I aC): estado de la cuestión, Itineràires des vins romaines en Gaule (F.Olmer, ed.), Monog. Arch. Mediterranea, Dossier 5. Lattes, 213-256.
VIVAR, G. (2013): El derelicte d'Illa Pedrosa. Comerç marítim i xarxes de distribució en época tardorepublicana al Mediterrani Centre-Occidental, Tesis inèdita, Universitat de Barcelona.

VOLPE, G. (1990): La Daunia nell'età della romanizzazione. Paesaggio agrario, produzione, scambi, Bari

VOLPE, G. (1995): Il contenitori da trasporto, Arpi. La tomba della Medusa e la necropoli (M. Mazzei, ed.), Bari 1995, 231-240.

ZAMORA, D.; GUITART, J.; GARCÍA, J. (1991): Fortificacions a la Laietània litoral: Burriac (Cabrera de Mar). Cap a un model interpretatiu de l'evolució del poblament ibèric laietà, Actes del Simposi Internacional d'Arqueologia Ibèrica. Fortificacions, Manresa, 337-353. 